Understanding Complex Systems

Springer:

COMPLEXITY

Hassan Qudrat-Ullah

Peter Tsasis Editors

Innovative

Healthcare

Systems for the

21 st Century

Springer 


\section{Editors}

Hassan Qudrat-Ullah

School of Administrative Studies

York University

Toronto, ON, Canada

\section{Peter Tsasis}

School of Health Policy and Mangement

\& School of Administrative Studies

York University

Toronto, ON, Canada
ISSN 1860-0832

Understanding Complex Systems

ISBN 978-3-319-55773-1

DOI $10.1007 / 978-3-319-55774-8$

Library of Congress Control Number: 2017939685

- Springer International Publishing AG 2017

This work is subject to copyright. All rights are reserved by the Publisher, whether the whole or part of the material is concerned, specifically the rights of translation, reprinting, reuse of illustrations, recitation. broadcasting, reproduction on microfilms or in any other physical way, and transmission or information storage and retrieval, electronic adaptation, computer software, or by similar or dissirtilar methodology now known or hereafter teveloped.

The use of general descriptive names, registered names, trademarks, service marks, etc. in this publication does not imply, even in the absence of a specific statement, that such names are exempt from the relevant protective laws and regulations and therefore free for general use.

The publisher, the authors and the editors are safe to assume that the advice and information in this book are believed to be true and accurate at the date of publication. Neither the publisher nor the authors or the editors give a wartanty, express or implied, with respect to the material contained herein or for any errors or omissions that may have been made. The publisher remains neutral with regard to juristictional claims in published maps and institutional affiliations.

Printed on acid-free paper

This Springer imprint is published by Springer Nature

The registered company is Springer International Publishing AG

The registered company address is: Gewerbestrasse 11, 6330 Cham, Switzerland 


\title{
Chapter 4 \\ Systemic Development of Health \\ Organizations: An Integrative Systems Methodology
}

\author{
Markus Schwaninger and Johann Klocker
}

\begin{abstract}
The purpose of this paper is helping managers and leaders in healthcare develop viable organizations that deliver high-level services. Health organizations such as hospitals are exceedingly complex. Therefore, we use Integrative Systems Methodology, a framework designed especially as an enabler for coping with complexity. Within that framework, we combine quantitative and qualitative methods to describe and explain organizational phenomena evolving over time. Rather than a large survey, we use a real-life case study. A single-case setting has been chosen, to enable long-term and in-depth exploration. The case spans 30 years, covering the evolution of the oncological care system of Carinthia, which is a federal state of Austria. The contribution of the chapter is in providing deep insights. It lays open the structures underlying the viability of health organizations. The chapter also provides well-grounded advice for how to build a robust health organization in a context of complexity and change.
\end{abstract}

Keywords Healthcare system • Organization design • Recursive structure $\bullet$ Viable System Model - Organizational change - Integrative Systems Methodology • Modeling • Simulation $\bullet$ System dynamics $\bullet$ Counterintuitive system behavior

\section{Introduction}

The purpose of this chapter is to make a contribution toward a more effective management of health organizations. We intend to show innovative ways for coping with the organizational complexities managers and leaders are facing in the healthcare sector. Our study should be of interest to both practitioners dealing

M. Schwaninger $(\varangle)$

University of St. Gallen, St. Gallen, Switzerland

e-mail: markus.schwaninger@unisg.ch

J. Klocker

Oncological Care System, Klagenfurt, Austria 
organizational development processes and academics of management science. For this aim, we are reverting to a systemic framework and conceptual tools, both tried and tested in empirical studies and many real-life applications.

This work therefore is grounded in systems theory and cybernetics, ${ }^{1}$ the scientific approach to dealing with organizational complexity. There are other theoretical schools that specialize in the modeling of complex systems, e.g., mathematical complexity theory. For the purpose of our study, the advantage of the systems approach is in its having developed concepts not only for modeling but also for steering dynamic social systems.

We conceive of health organizations as complex dynamic systems delivering health services while striving for viability and development. This system-theoretic stance is distinct from a purely economic view, as it is based on a transdisciplinary concept that includes other dimensions, namely, ecological, social, and economic ones, in an integrative manner (Ulrich 2001).

The promise of such a systemic approach is to lead the management beyond the reductionist, short-term-focused, and fragmented approaches which are still a fact of life among organizations in the healthcare sector (Erbsen 2012).

We will use a case study of an exceptionally long-term development of a healthcare system, to flesh out insights for the development of successful healthcare organizations.

We first outline the methodological orientation of our inquiry. Thereafter, we introduce Integrative Systems Methodology (ISM), a framework for dealing with complex issues. In the next section, a rich case study is set forth, as a vehicle for a systemic view on the development of health organizations. In describing the evolution of the healthcare system under study, we move from its origins to a diagnostic and then design mode, covering a span of 30 years. In each section, specific methods and conceptual tools will be used in such a way that readers can apply them immediately. Following the first 25 years (Phase I) of the case study, we consult empirical data if they justify the claim of effectiveness of the healthcare system under study. With regard to the last 5 years (Phase II), we show how a new stage in the development of that system brought about unexpected change. For each one of these phases, substantial insights and conclusions are presented. At the end of the paper, a synopsis of both substantive and methodological aspects of the chapter is provided. In particular, we reflect upon the methodological role of the ISM framework.

\footnotetext{
${ }^{1}$ The systems approach embodies a transdisciplinary search for principles and isomorphisms (structural invariances) manifest in organized wholes of all kinds, such as technological, biological, and social systems. An operational definition for the present study: systems theory is a formal theory, which transcends single disciplines, for the description, explanation, and design of systems, i.e., organized wholes. The focus of systems theory is on common principles in the structure and operation of systems of all kinds (von Bertalanffy 1968; Laszlo 1996; Hammond 2003). Related terms such as systems thinking, systems view, and systems approach are often used as synonyms for systems theory. Cybernetics, the science of communication and control in and of dynamic, complex systems (Wiener 1948), can be considered a subset of systems theory. The concepts of systems theory in general and cybernetics in particular have proved to be a strong basis for a management science dealing with broad, complex issues requiring an integrative, transdisciplinary treatment (Ulrich 2001).
} 


\section{Methodology}

\subsection{Alternative Frameworks}

To make sense of the complex case study we are presenting, we will make use of the conceptual framework of Integrative Systems Methodology (ISM). This is a systemic framework designed to help managers in coping with organizational complexity or, more precisely, to attain requisite variety ${ }^{2}$ in relation to confronted problems. The attribute "systemic" is used in this context to denote that the framework is grounded in systems theory and cybernetics, the science dedicated to holistic or integrative management in the face of organizational complexity. This framework has been tested in multiple settings, some of which are documented in published case studies (e.g., Weber and Schwaninger 2002; Schwaninger 2004, 2013).

The ISM framework is a vehicle for combining qualitative and quantitative methods of dealing with organizational complexity. There are other "multimethodological" frameworks with similar aims. Going back to earlier works (Flood and Jackson 1991; Mingers and Gill 1997; Schwaninger 1997; Tashakkori and Teddlie 1998; Brewer and Hunter 2006), the quest for combining methods has become the "third methodological movement in social research" (Tashakkori and Teddlie 2010; Morgan 2014). The proposed frameworks range from highly abstract to highly concrete versions and from those addressing academic research to those referencing practical problem-solving. ISM is focused on facilitating applied research and helping practitioners cope with complexity.

In positioning Integrative Systems Methodology (ISM) among the variety of pertinent approaches, two aspects stand out. Firstly, it addresses the need of organizational and human agents to achieve requisite variety, i.e., a repertory of potential behaviors that is commensurate with the variety of the situation or agents it is confronted with. Secondly, ISM, albeit being open to the inclusion of different methods both quantitative and qualitative, has been focusing on two highly complementary methodologies that are combined in a rigorous manner. One is the Viable System Model (Beer 1979, 1981, 1985), the other being system dynamics (Forrester 1961; Sterman 2000). Both are at the core of the methodological repertory of systems theory and cybernetics. These two aspects indicate the use of ISM in the context of the case to be studied here.

\footnotetext{
${ }^{2}$ Variety is a measure and a synonym for "complexity." The concept of "requisite variety" stems from the cybernetician Ross W. Ashby. The condensed version of Ashby's law of requisite variety is: "Only variety can absorb variety" (Ashby 1956; the verb "absorb" was substituted for the original "destroy," by Stafford Beer (passim)).
} 


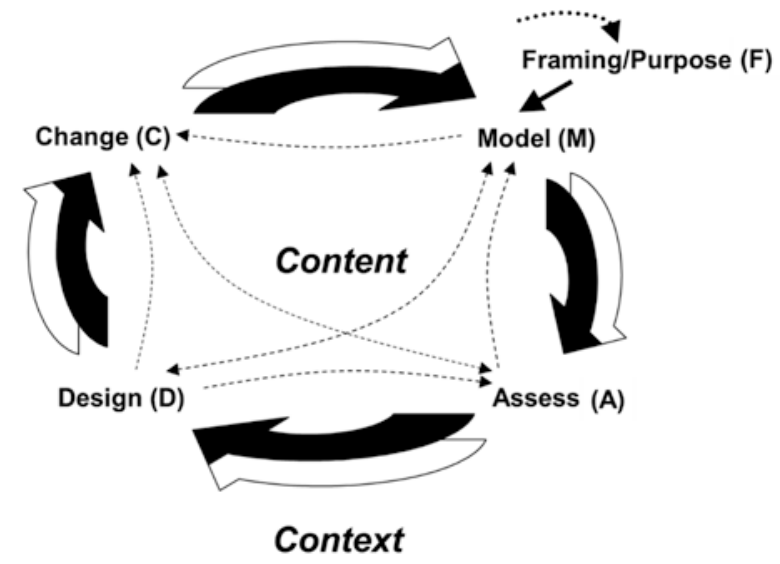

Fig. 4.1 An integrative systems methodology for dealing with complex issues—process diagram (this scheme was inspired by earlier works of the cybernetician Raúl Espejo (1993) and associates (e.g., Espejo and Reyes 2011), namely, his cybernetic methodology, and by the postulate to study content, context, and process of change, as formulated by the organization scientist Andrew Pettigrew (1985): 50)

\subsection{Integrative Systems Methodology}

Integrative System Methodology (ISM) is a heuristic framework ${ }^{3}$ by which problemsolvers can enhance their behavioral repertoire (cybernetically, "variety"; Ashby 1956) in dealing with complex issues or problems. When dealing with complex phenomena, the procedure usually adopted follows a set of steps such as (Fig. 4.1) model (formal or informal representation), assess (diagnosis), design (strategies, structures, etc.), and change (of the system). The point of origin is a perspective, i.e., a conceptual frame and a purpose or "overall goal" (Schwaninger 1997, 2004).

From dealing with complex organizational processes, such as the one developed here, an important insight has emerged: in rather complex cases, the process and the problem solution must be developed at two levels, content and organizational context. If one works only on the content, the problem solution will probably be realized defectively. If only context is considered, a dearth of knowledge for providing good solutions will likely occur. To distinguish the two dimensions, the arrows in Fig. 4.1 are two-colored. The process is denoted by these arrows.

With "content" we are referring to the activities or operations of the system under study, and with "context" to the structural and cultural frame into which it is embedded. Content is about what the system "does"; context is about how it organizes itself (or how it is organized). Both of these dimensions require different conceptual tools for dealing with complexity. In the following, we will use two systemic meth-

\footnotetext{
3 "Heuristic" can best be translated as "the art of finding." Stafford Beer defines "heuristic," a contraction of "heuristic method," as "a set of instructions for searching out an unknown goal by exploration, which continuously or repeatedly evaluates progress according to some known criterion" (Beer 1981: 402).
} 
ods, system dynamics modeling at the content level and cybernetic modeling for context. The two loops in Fig. 4.1 are separated only for the purpose of analysis. In fact, they are intertwined and in practice show overlaps. They revolve iteratively, alongside a set of operations. The number of these operations could vary as a function of the notation. Here, besides framing/defining purpose, a set of four operations is used-modeling, assessing, designing, and changing — which can be sufficiently well distinguished and specified.

For a more detailed schema, see Schwaninger (2004, 2013) and Gomez and Probst (1987).

Given the circular structure of the process, one could start anywhere with its description. Also, in actual practice, the starting point could be anywhere. We shall take "framing" (F), including such aspects as purpose and goals or aims as the point to start with, framing being a kind of anchor for sensemaking. It addresses fundamental issues: Which are the purpose and aim of the process? What is the systemin-focus? Which are the relevant perspectives? These are questions that should be dealt with early on. Modeling (M) then includes tasks such as specifying the goals of stakeholders and the factors critical for attaining those goals, foregrounding issues, and elaborating models. Assessing (A) comprises tasks such as apprehending the dynamics of the system, simulating and exploring scenarios, as well as interpreting and evaluating simulation outcomes.

Designing (D) includes tasks such as ascertaining control levers and designing strategies, organizational contexts, and action programs. Under the term "change," all the tasks that encompass the realization of strategies and action programs are included. All of these operations are about enhancing systemic evolution.

Please note that "design" in a wider sense encompasses earlier tasks such as modeling and assessment. Anyhow, the diagram shows that the process is not the sequential procedure which the main arrows might suggest. As the additional dashed lines show, the process is characterized by multiple communication processes involving feedback, validation, and control. "Feedback" here occurs when results and insights are fed back to earlier phases, e.g., from design to model. "Validation" is a process by which the quality of models and strategies is constantly improved. Finally, "control" is the process by which results are compared to goals, with the ensuing steering and regulation, when necessary. The schema is a simplification, which focuses on the general process characteristics, without any claim to final completeness.

Adhering to the aim of maximizing space for the substantive issues of the case study, we will refrain from bringing in the more detailed presentation of ISM, which has been published elsewhere (Schwaninger 1997, 2004, 2013). The main point about the diagram of Fig. 4.1 in the context of socio-technical system design is the need for proceeding simultaneously at the content and context levels: (a) resolving the issue as regards content and (b) embedding the process in a supportive organizational context. In the following, the abbreviations used for the phases in the diagram—F (framing), M (modeling), A (assessment), D (design), and C (change)—will be used to denote the sections of the case study. 


\section{Introduction to the Case Study ${ }^{4}$}

\subsection{Background}

Over several decades, healthcare systems all over the world have been grappling with a formidable challenge. The issue is providing an integral kind of care, with the patient at the center, rather than technology or doctors. Traditionally, over the last four or five decades, hospitals have increasingly suffered from an orientation that hinges on overspecialization and splintered forms of organization. This orientation threatens the quality of medical care, because patients tend to be treated in a fragmentary way. The perspective on sick persons is as if they were conglomerates of organs that can be treated in isolation. The focus is on symptoms. Healthcare systems often lack the ability to deal with syndromes that can have multiple causes with complex interrelationships. Normally, the main concern is applying high technology and advanced medication, instead of warranting patients' quality of life.

These deficits have provoked calls for a holistic kind of treatment. The systemic, integrative properties of such an approach to medicine had been underresearched because it transcends the silos of research organizations.

Hence, our research question is: "How must healthcare systems be designed to achieve viability or, more concretely, to become both efficient and effective while also maintaining their identity in the long run?" The issue here is building a system that provides patient-centered care of excellent quality and at bearable cost.

The main topic of this chapter is organization. This is a transdisciplinary, sociotechnical undertaking with far-reaching implications. Organizational innovation is needed: it can yield better and more abundant fruits than mere technological creations can.

The purpose of this chapter is to explore an exemplar of a long-term process aimed at achieving a holistic system design of a viable organization. The case is from healthcare. We trace back the process by which a comprehensive oncological care system was built in the Austrian province of Carinthia, Austria, with Klagenfurt as its capital. The study covers a period of roughly 30 years, until 2015. We do not only report on successes but also the, albeit sparse, downsides along that way.

\subsection{Origins}

To start with, a clarification of the role of the authors is needed; for their names, we will use the abbreviations MS and JK. In 1984, JK was put in charge of building an oncological care unit situated in the department of internal medicine at the central

\footnotetext{
${ }^{4}$ The following version draws on a paper that was written earlier (Schwaninger and Klocker 2017a), which is expanded here. In particular, the account of qualitative modeling is now complemented by a record of quantitative modeling. The main body of our narrative covers, first, the evolution of the system under study from 1985 to 2010. Second, we will look at a changing situation that emerged in the years 2011-2015.
} 
hospital (Landeskrankenhaus, in short "LKH") in Klagenfurt, the capital of Carinthia, one of the nine federal states of Austria. Over the ensuing 30+ years, JK pioneered and directed the development of an oncological care system covering the whole state and involving ten hospitals as well as multiple local physicians. He has managed that system over all these years and is the main source of information for this case study. Early on, in 1985, he called in MS, who is an organization scientist, to help him conceptually, as a consultant and coach, a role that he continues to hold. According to JK, much of the successful evolution of that healthcare system is due to that cooperation. Normally, MS did not appear in front of the staff of the unit, except at certain internal conferences and workshops, for talks and discussions related to the organization and leadership of the system under development.

Oncology, the domain of medicine that deals with tumors, is an interdisciplinary field, by definition. It involves virtually all medical disciplines-internal medicine, radiology, surgery, gynecology, orthopedics, neurology, urology, pneumology, hematology, etc. First of all, cancer can appear in any organ of the human body. Second, its therapy often requires a combination of measures, such as medical tumor treatment (chemotherapy, hormone therapy, immunotherapy, and antibody therapy), radiotherapy, surgery, and psychosocial care. Third, the approaches to therapy are manifold. That has been primarily a consequence of the complexity of the cancer problem, but also of the relative youth of oncology as a field, back in 1985. For most therapies at that time, the physician could not rely on a trusted basis for decision-making, while the progress in pharmacology and medicinal technology kept shaping new recommendations and facilities.

In that situation, the chosen form of therapy often was less a function of the patient's syndrome than of the methods which the respective therapist mastered or was especially interested in. To formulate it in a pointed way, if the patient landed in the hands of a surgeon, he or she had a surgery. In case they were under treatment with an internist, they had to undergo chemotherapy, and under the auspices of the radiotherapist, they would undergo radiotherapy.

In contrast, the desirable approach for an oncological care system (OCS) would necessarily use all available therapeutic modalities and infrastructure, in a sequential or combined mode, and customized to each specific case.

We will now describe the organizational development process, following the logic of Fig. 4.1.

\subsection{Framing: Purpose and Overall Goals $(F)$}

JK and the directors of the state health authority, with the directors of the LKH Klagenfurt, shared a common vision. They defined the purpose of Oncology Carinthia as a health system that should provide the highest possible level of oncological care covering the whole country. They then agreed upon three general goals:

(a) Guarantee of excellent oncological care in the context of the central hospital, using all the resources available within that powerful institution. 
(b) Provision of fast and high-level care for oncological patients all over the federal state, i.e., also outside the capital—in small towns and in the countryside, as far as possible "on the spot."

(c) An increasingly preventive orientation of oncological medicine in Carinthia.

\subsection{Mapping the System at the Outset (M)}

We will now sketch the actual and potential components of the system and the initial steps in the making of the oncological care system. Carinthia covers an area of $9500 \mathrm{~km}^{2}$ and had about 500,000 inhabitants at the time. The socio-geographic structure was "healthy," with no excessive urban concentrations. Besides the capital Klagenfurt (86,000 inhabitants), several district centers exhibited their own lively economic, social, and cultural activities. Altogether, Carinthia had 10 hospitals potentially apt to be included in a network of oncological care. Four of them were public (Landeskrankenhäuser-short "LKH"), and the rest private or of a religious order, as in the case of St. Veit (Krankenhäuser, short KH, or Sanatorien, short SAN). The number of independent physicians included about 20 internists, of which only one specialized in oncology. Many of them were also candidates for joining the network, to provide supportive care.

Statistically, 3000 new cancer incidences per year could be expected, $40 \%$ of them within the zone of Klagenfurt. The rest was distributed among three regions:

- Villach, Spittal, Laas: $30 \%$

- Wolfsberg: $20 \%$

- Friesach, St. Veit: $10 \%$

These zones are denoted approximately in the map (Fig. 4.2).

Assuming a 50\% 5-year survival rate, the yearly stock of incidences to be cared for was around $11,000,{ }^{5}$ either by acute treatment or by follow-up therapy.

In a conversation between JK and the director of the LKH Klagenfurt toward the end of 1984, some vital issues for the joint endeavor were raised ${ }^{6}$ :

JK: "There is no infrastructure for a serious oncological treatment. ..."

Director: "What do you mean by serious oncological treatment?"

JK outlines his concept of an interdisciplinary, holistic care that reaches the population in both the rural and urban areas. He pleads for a network organization, encompassing all relevant resources across the state, to ensure excellent care services all over Carinthia. He also makes his vision of medical care concrete: holistic treatment, according to that vision, is integral in that it conceives of the patient as a unity, not as a collection of parts to be treated. Holistic treatment is also inclusive in

\footnotetext{
${ }^{5}$ The new incidences $(3,000$ p.a.) are a flow, while the incidences to be cared for $(11,000)$ are a stock.

${ }^{6}$ For details, see Schwaninger and Klocker (2017a).
} 

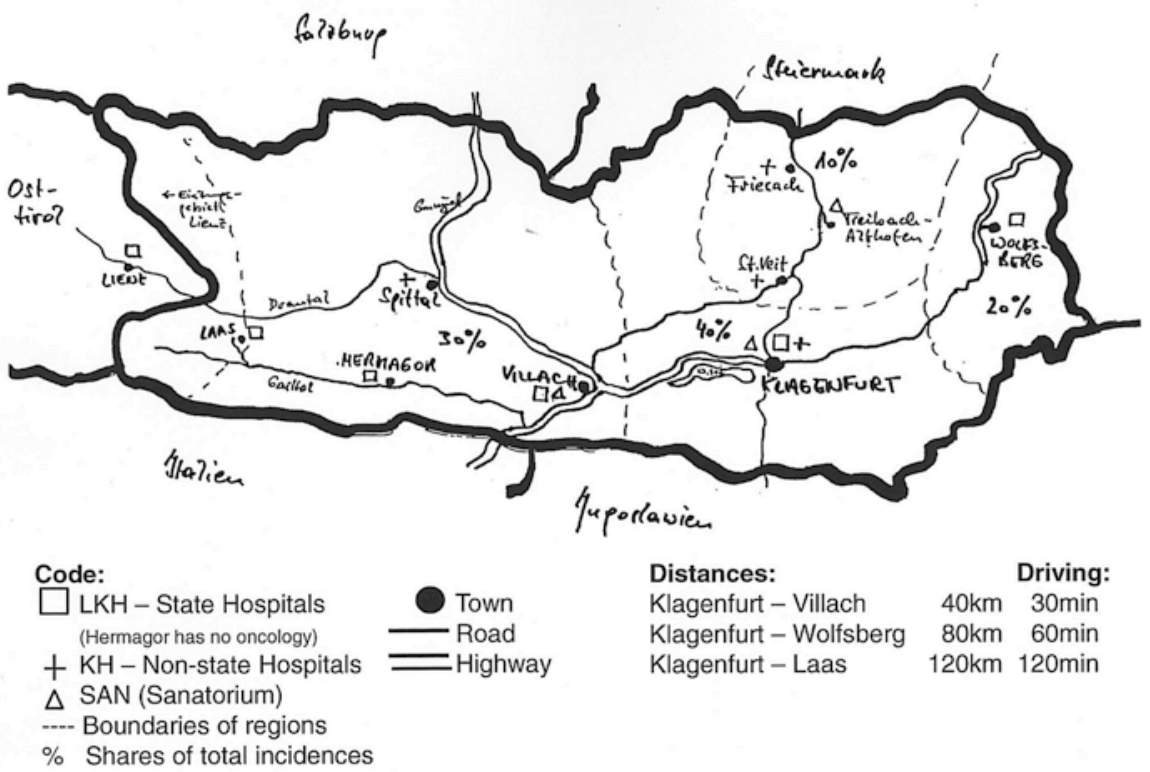

Distances:

Klagenfurt - Villach $\quad 40 \mathrm{~km} \quad 30 \mathrm{~min}$

Klagenfurt-Wolfsberg $80 \mathrm{~km} \quad 60 \mathrm{~min}$

Klagenfurt - Laas

$120 \mathrm{~km} 120 \mathrm{~min}$

Fig. 4.2 Map of Carinthia with hospitals

that the patient and his or her family are included in the process of care as responsible agents. Even more, the patient is the Archimedean point here. Holistic system design conceives the health organization as a purposeful system striving for viability and development. It is an organizational design that transcends the borders of departments, enabling transdisciplinary collaboration across the system.

After a longer discussion, the two agreed on a realistic first objective: the buildup of an oncological care unit centered in Klagenfurt. This would comprehend an allotment of ten beds for intensive therapeutic situations and an ambulatory where patients could be treated and also, once therapy was concluded, receive aftercare.

Subsequently, the LKH management endowed JK with the mission of building a consultation service involving other hospitals.

JK had collected practical and scientific experience on the matter "cancer" over years, including work at a Swiss oncological center with a worldwide reputation for both its management and doctors. He knew that in addition to the professional, medicinal aspects, he would be confronted with demanding organizational and leadership issues in order to achieve his goals. He was fully aware that the medical infrastructure lagged behind what he envisioned. Concerning structural aspects of the emerging system, he was clear about several points:

(a) He calculated that the necessary size for a healthcare center with oncological focus needed to serve a catchment area for between 200,000 and 500,000 to 550,000 inhabitants. Carinthia was in that range. 
(b) He had a precise idea of a structure for interdisciplinary work. Two experienced and highly competent oncologists would be needed, one with an internist and one with a radiology background. Such a team could cover the ambulant part as well: treatment, aftercare, and consulting, including the maintenance and orchestration of relationships with the specialized departments, for example, surgery, urology, otolaryngology, etc. But that is only part of the story. For cases of cancer in wards for gynecology, otolaryngology, pediatrics, or pneumology, interdisciplinarity always means that the pertinent specialists call on the oncologists. The treatment should be planned under the lead of the oncologists, while the therapy and aftercare should be carried out by the specialists. In the aftercare phase, local independent physicians can also become active.

(c) Not all activities in the chain detection $\rightarrow$ diagnosis $\rightarrow$ therapy $\rightarrow$ aftercare needed to be performed in the ambulatories and wards of hospitals. Simpler forms of therapy and certain measures of follow-up care could be delegated to independent general practitioners and specialists.

(d) Prospects should be treated only as in-patients if absolutely necessary, e.g., in case of major surgeries, but then be relegated to the ambulant mode.

(e) He estimated that about two thirds of the cases would fall under the domain of internists and the rest to other departments.

\section{Phase I: 1985-2010}

This phase spans a quarter of a century. It includes the formation of the new oncological care system (OCS), its evolution, and its successful operation over 25 years. We will outline the main developments in the three dimensions of Integrative Systems Methodology_content, context, and process.

\subsection{Content: Phase I (From Vision to Models)}

Under the keyword "content," the substantive issues and decisions concerning the establishment of the OCS will be addressed. This is about "what the system does" and how it functions.

\subsubsection{A First Model (M) and Assessment (A)}

Early on, JK and MS drew a first model, using the methodology of qualitative system dynamics, to provide an overview of the most important factors making up the system-in-focus, and their dynamic interrelationships. Their aim was first to understand and assess "how the system ticks." Secondly, they wanted to discover priorities and levers for the design of the system. 
Table 4.1 Stakeholders, goals, and key factors

\begin{tabular}{l|l|l}
\hline Interest groups & Goals & Key factors \\
\hline Patients and their families & $\begin{array}{l}\text { Be healthy } \\
\text { Suffer little }\end{array}$ & $\begin{array}{l}\text { Prevention } \\
\text { Quality of life } \\
\text { Quality of care }\end{array}$ \\
\hline Champions of oncological care & $\begin{array}{l}\text { Be excellent } \\
\text { professionals } \\
\text { Have an interesting job } \\
\text { Realize their ideas } \\
\text { Lead an effective team } \\
\text { management } \\
\text { Strong infrastructure } \\
\text { Cooperation } \\
\text { Effective coordination }\end{array}$ \\
\hline Local hospitals and doctors & $\begin{array}{l}\text { Quality in oncology } \\
\text { Become members of } \\
\text { care network }\end{array}$ & $\begin{array}{l}\text { Training } \\
\text { Cooperation }\end{array}$ \\
\hline Professional staff & $\begin{array}{l}\text { Have an interesting job } \\
\text { Have a bearable job } \\
\text { Become more qualified }\end{array}$ & $\begin{array}{l}\text { Training } \\
\text { Psychohygiene } \\
\text { Cooperativeness of other units } \\
\text { involved }\end{array}$ \\
\hline $\begin{array}{l}\text { State authorities and central } \\
\text { hospitals administration }\end{array}$ & $\begin{array}{l}\text { Effectiveness of care } \\
\text { system } \\
\text { Efficiency of care system }\end{array}$ & $\begin{array}{l}\text { Low incidence of cancer } \\
\text { Cancer prevention } \\
\text { Success of care } \\
\text { High productivity } \\
\text { Coordination }\end{array}$ \\
\hline Public in general & $\begin{array}{l}\text { Social and ecological } \\
\text { consciousness } \\
\text { Quality of environment } \\
\text { Healthy behavior }\end{array}$ \\
\hline
\end{tabular}

The goals and key factors stand for components-potential variables or parameters that may constitute a model of the system under study, such as the one in Fig. 4.3, that is, a causal loop diagram (CLD) (CLDs are devices stemming from system dynamics, a methodology for modeling and simulation, going back to Prof. Jay Forrester (see Forrester 1961; Senge 1990; Sterman 2000), i.e., a qualitative representation giving a first idea of the dynamics of that system)

They attempted to elicit the relevant perspectives on the system-in-focus. The schema in Table 4.1 distinguishes the main stakeholder groups ("interest groups") and their goals with respect to the system-in-focus. Then the key factors, i.e., aspects that are critical for the attainment of these goals, are ascertained.

Figure 4.3 shows a CLD, - a qualitative model (often called "mental model"), giving a first idea of the forces that govern the dynamics of the OCS. In the diagram, arrows denote causal relationships, and signs show the directions of these relationships. All arrows that carry a negative sign denote that the two connected variables point in opposite directions, e.g., more personnel turnover leads to less productivity (and less personnel turnover leads to more productivity). All arrows not provided with signs implicitly show connections of variables pointing in the same direction, e.g., more quality of care entails higher success of care. ${ }^{7}$ The diagram shows nine

\footnotetext{
${ }^{7}$ To make generally correct the statement " $\mathrm{X}$ and $\mathrm{Y}$ move in the same [opposite] direction," a more precise formulation is necessary: "If X increases, $\mathrm{Y}$ increases above [below] what it would have been" (Richardson 1997).
} 


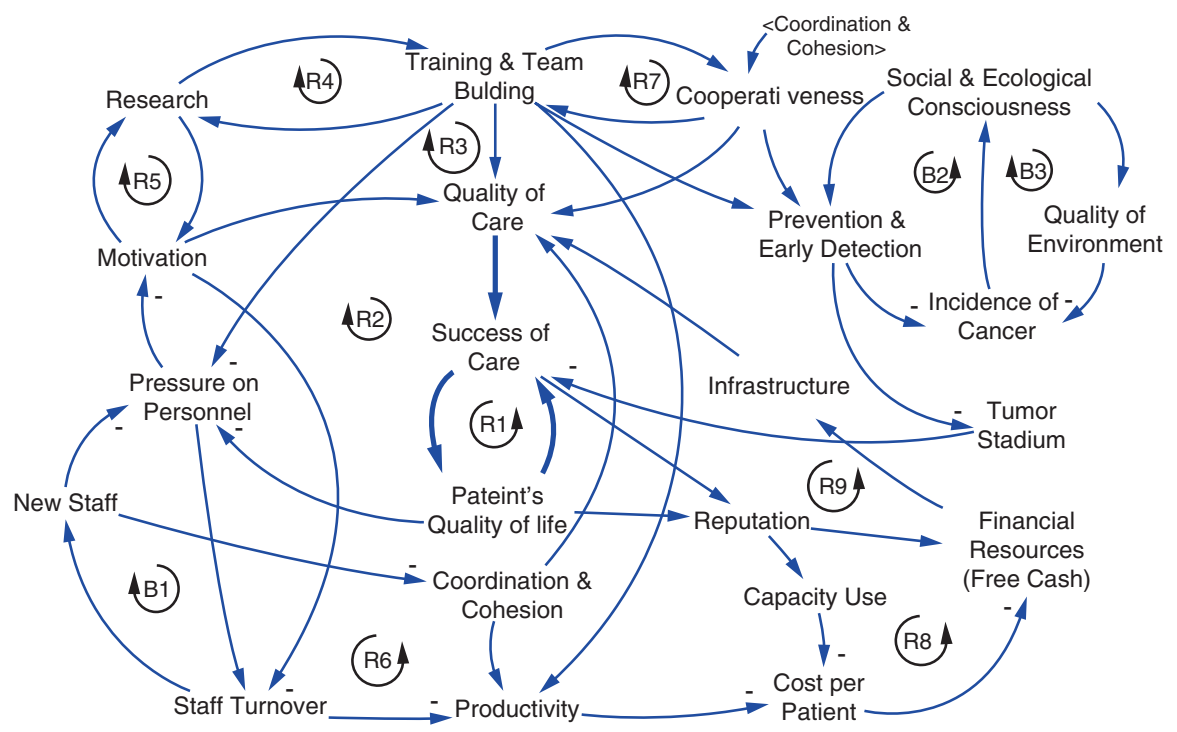

Fig. 4.3 Causal loop diagram showing the dynamics of the system-in-focus

reinforcing ("R") and three balancing ("B") loops. The polarity of a loop is the result of a multiplication of all signs in that loop. Loops with even numbers of negative signs are always reinforcing (e.g., Loop R1 [zero minuses]: "+" * “+” = "+"; Loop R8 [two minuses]: “+” * “_”* “_”* “+”...). Loops with uneven numbers of negative signs are always balancing (e.g., Loop B1: “+”* “-”* “+” = “-”). Reinforcing loops promote either increase or decrease, both of which, if not attenuated at some point, will entail destabilization eventually. Balancing loops lead to attenuation and potentially to equilibrium. The benefit of distinguishing these two kinds of loop is in that those dynamics can be identified which make the system develop on the one hand and which lead to a balance of the system on the other hand. For technical details, see Sterman (2000: Chap. 5).

The number of reinforcing loops is higher than that of the balancing loops, because Oncology Carinthia is still in an early phase, heading for development. A brief summary will uncover the meaning of these loops:

R1: the core loop, a "motor," where a patient's quality of life is a function of quality of care entailing successful care. The quality of life for patients dynamizes successful care, because patients can contribute more to the healing process and to a positively spirited milieu.

R2: the motivation loop: motivation drives the quality of care and is driven by successful care and the patients' quality of life.

R3: the qualification loop: training enhances quality of care, which motivates people. Motivated doctors engage in research, which improves training activities.

R4: the knowledge loop, where research and training dynamize each other. 
R5: the research loop: professionals' motivation thrives on their research engagement, and motivation triggers commitment to that additional work.

R6: the productivity loop: productivity is strongly affected by quality and success of care, which reduce pressure on personnel and staff turnover. Productivity strengthens the financial position and thereupon the infrastructure, which is a prerequisite for service quality.

R7: the cooperation loop: cooperativeness, which is itself driven by coordination and team cohesion, triggers competence enhancement, expressed in training and team building.

R8: the financial loop: the reputation of the oncological care system attracts new patients, leading to higher capacity use. As the cost per patient is diminished, the financial and infrastructural position improves. So do the quality and success of care, which again strengthen the reputation.

R9: the external funds loop: this loop is similar to R8, but it shows a direct link from reputation to financial resources, denoting an improved position for gaining funds from external sponsors.

B1: the personnel dynamics loop: staff turnover implies staff leaving and new staff coming in. The higher that index is, the less pressure on personnel (new staff $\rightarrow$ pressure on personnel has a negative link); and thus less pressure on personnel decreases staff turnover. This is a balancing loop that regulates (balances, controls) turnover through new staff since new staff decrease pressure.

B2: the prevention loop: incidence of cancer is regulated (balanced, controlled), to some extent, through consciousness, preventions, and early detection, which lead to lower incidences of cancer.

B3: the ecological loop: incidence of cancer is regulated (balanced, controlled), to some extent, through consciousness and quality of environment, which lead to lower incidences of cancer.

Loops B2 and B3 hypothesize very long-term dynamics, congruent with the vision that prevention should have greater prominence in Carinthia than in the past.

The logical structure and the impact of the CLD highlight the crucial role of quality of care, patients' quality of life, and the priority of the human resources over financial and infrastructural resources.

This CLD is focused on aspects of content (inner loop of Fig. 4.1). It helped in understanding how the system worked and was also used at various stages when scenarios of the development of the system were discussed. The CLD signaled those "places" where interventions would be indicated. In Sects. 4.1.3 and 4.2.1, we will describe how the respective measures were taken.

\subsubsection{The Challenge Ahead}

The idea of the champions was, first of all, to set the norm to enable an excellent level of care (including quality, reliability, and high speed). Strategically, that care had to be delivered locally, i.e., be as decentralized as possible, and central only where absolutely necessary, with intelligent use of all available resources. 
There were problems ahead:

- Resistance of medical departments that should join the effort

- Weak know-how and lack of interest among the peripheral hospitals

- Deficits of knowledge among the independent physicians

- Fear among doctors and nursing staff of increasing demands and uncertainties

- Low motivation among staff

- No formal authority among oncologists about parties that should be included

- Scarce budgetary means

- Limited personnel capacity in the central oncology unit

- Low interest, among authorities, in preventive care

In the face of these issues, the challenges presented themselves as follows:

- Winning the cooperation of medical departments at the Klagenfurt and peripheral hospitals.

- Multiply know-how and enhance knowledge building in the peripheral hospitals.

- Involve and link multiple resources.

- Create robust and nimble structures to enhance the viability of the oncological care system.

- Information management-make data and information available for the control of therapies and the creation of new therapy options.

- Balance decentralized and centralized care.

- Balance the efficiency of care operations and the effectiveness of care strategies.

In sum, the venture ahead was very demanding: a high diversity of tasks had to be achieved, distributed human and technical capacities had to be networked skillfully, flexibility was to be built, and the restriction of high scarcity of resources had to be taken into account.

\subsubsection{A First Take on Design (D): Ascertaining Levers}

The CLD in Fig. 4.3 reveals tangible dynamic features. From there, the next question follows naturally: Which are the levers to improve the system in line with the purpose and goals as defined at the outset? At that point the goals were already much more concrete and integrated in the model of the whole system, because the variables were derived from the key factors representing all stakeholders.

Model analysis directed our attention to three main levers, (a) psycho-hygiene for the staff; (b) structures, information systems, and knowledge management; and (c) leadership (bold parameters in Fig. 4.4). The kinds of interventions chosen thereupon were not a result of the CLD per se, but they emerged in the champions' ongoing discussion of challenges and pertinent responses. The CLD made the "mechanisms" driving the system under study transparent. Hence, it was a vehicle 


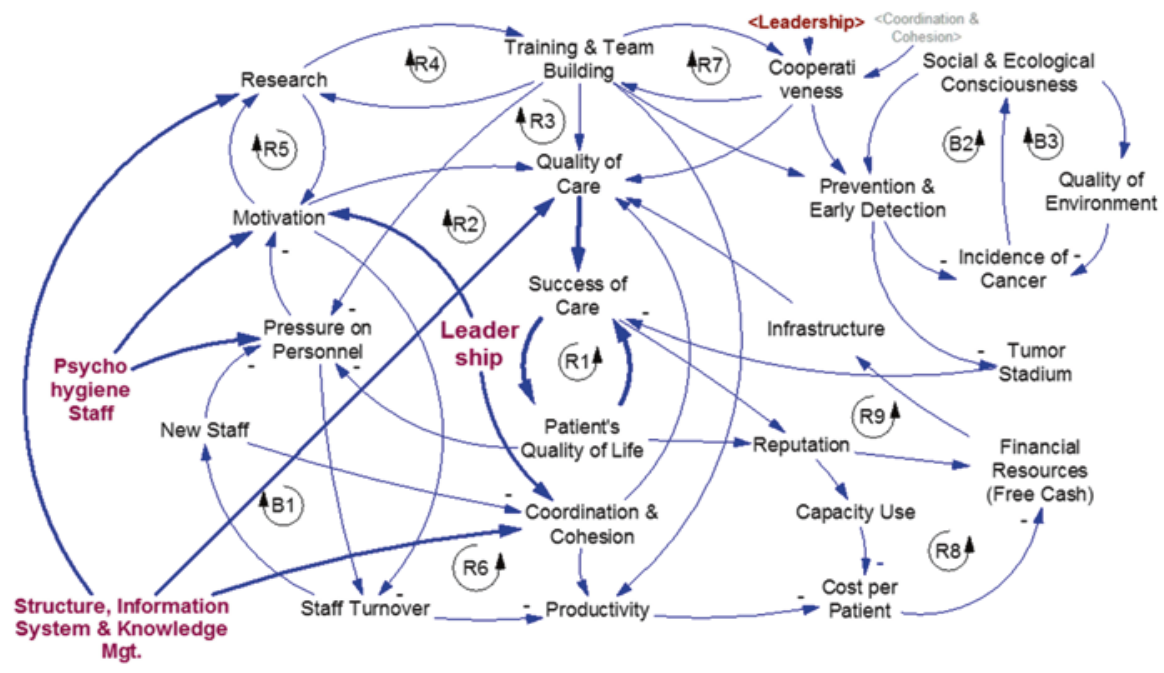

Fig. 4.4 Three main levers for the development of the oncological care system (Variables in brackets are "shadow variables," used to avoid entanglements in the diagram. For example $<$ Leadership > is identical with Leadership)

for keeping that discourse going. In the ensuing efforts, the identified levers were put into practice in sophisticated ways, as will be shown.

These levers have the character of strategic parameters with great potential:

(a) Psycho-hygiene: The staff in oncological care is subject to a stress load that tends to be greater than in other professions. Therefore, introducing psychohygienic measures was crucial, to sustain and foster the psychic health of people, adopting both preventive and restitutive measures.

(b) Structure, information system and knowledge management: Structure is a powerful device that was considered crucial for strengthening quality of care, coordination, and team cohesion. In addition, information systems and knowledge management were prominent in strengthening research.

(c) Leadership: Ultimately, everything in an organization is subject to the influence of leadership and hinges on its quality. Motivation and coordination and cohesion were identified as main aspects to be strengthened by that driver. Coordination and cohesion then impinge strongly on cooperation. Equally crucial was a major effort to win the cooperation of all necessary parties.

Moving these levers served to create a context (outer loop Fig. 4.1) that would govern what we call "content" - the operating activities of the oncological care system (OCS). The context parameters proved highly effectual in changing the dynamics of the content variables (Fig. 4.3). 


\subsection{Context: Phase 1 (Organizational Aspects)}

Under the keyword "context," the issues of structure and leadership in the OCS will be addressed. These are about those aspects which define how the system under study is organized (or organizes itself) in order to make viable "what the system does."

\subsubsection{From Design (D) to Change (C)}

The levers ascertained in the last section were used early on to develop the system, and they go on being important today. First of all, leadership was strong from the start, when the champions took over the mandate to build a new OCS. To make their moves successful, the champions adhered to certain strategic leadership principles (Malik 2008), e.g.:

- Show competence; be modest, reliable, and persistent: competence in oncological matters, demonstrated humbly, was the way to be accepted for the champions, who gradually gained an image of reliable, enduring partners.

- Be cooperative and complaisant: instead of imposing their position, they opened a dialogue, leading to a game in which both sides could win.

- Learn ambiguity tolerance: this was necessary for becoming able to live with the trade-offs that always emerge in situations with multiple players.

- Explain one's own behavior: some of the champions' moves were bold. They had to explain themselves in order to win acceptance.

- Training by practice and by attractive events: knowledge building was a key issue. As people embodied that knowledge, both learning-on-the-job and cultural events which fostered the interchange of people were imperative.

- Convince by evidence and results: the champions started with modest but promising results, avoiding big words and letting events speak for themselves.

- Constructive tenor: negative critique was avoided, and the whole discourse led to a buildup of positive energy in the team, which gained cohesion and momentum.

Second, the leadership was not only competent and focused on substantive matters; it was also perpetually concerned with human beings - patients and staff. This humanistic orientation was very effective in salutogenic terms. ${ }^{8}$ But it was also very demanding for the staff. The permanent confrontation with difficult situationsstrenuous health conditions, tortuous treatments, and troublesome fates-tended to exhaust nurses and doctors. The leaders of the OCS were perfectly aware that given these sociopsychological conditions, a special treatment of the staff was required: they called it psycho-hygiene and gave it highest priority (together with quality of care).

\footnotetext{
${ }^{8}$ The term "salutogenesis" derives from the Latin "salus," health, and the Greek "genesis," generation, origin. The salutogenic framework (Antonovsky 1987) conceptualizes an approach to healthcare that concentrates on the factors supporting health and well-being rather than the factors causing disease.
} 
Measures taken included scheduled, structured, and at the same time easygoing team sessions, team supervision, and officers of psycho-oncological seminars with self-experience, yoga, drumming workshops, round dance, etc.

Third, organizational structure was crucial to enable the people working in the OCS. The first structural provisions aimed at winning the cooperation of the departments and peripheral hospitals. Our approach encompassed:

- Offering knowledge and support

- Regular meetings (tumor boards) and ad hoc meetings (tumor councils)

- Offering permanent readiness of oncologists for consultation about difficult cases (hotline for inquiries)

- Active duty $7 \times 24 \mathrm{~h}$ for emergencies

- Initially focusing on easy, success-prone treatments

- Regular educational events, which included presentations on therapeutic successes

Two concepts of this design need to be specified: besides the typical regular department meetings, two forms of teamwork were systematically cultivated, namely, tumor boards and councils. A tumor board is an interdisciplinary body at the hospital level, which brings together doctors of the site dealing with tumor cases, with the support of an oncology team member. It takes place in a fixed rhythm and deals with the set of current tumor cases of the hospital: diagnosis and therapy are discussed, and a decision on how to proceed is taken (by consensus). The second kind, tumor councils, is meetings where doctors in charge of one or more cases, supported by oncologists, go to patients and confer on the spot. Normally, such councils are invoked by the patron of a case in one of the specialized departments (e.g., surgery or gynecology) in those cases which cannot be taken care of by the regular tumor board, e.g., given their urgency. These two concepts are crucial for the evolution of the OCS and will be taken up later. For more about structural change, see next section.

\subsubsection{Progress in Organizational Design (D)}

As this is a chapter in a book about the design of healthcare systems, we are emphasizing the structural aspects of organizing (context loop in Fig. 4.1). We are focusing on design, transformation, problem-solving, and controlled experimentation. Indeed, the first thing we designed in Oncology Carinthia was organization structure, in order to put the normative principles and strategic orientation into practice.

The structural diagnosis and design of the OCS was of primary importance in the evolution of that system. Structure is not merely the expression of a state, for it changes behavior. And change was needed if the oncological system was going to take shape. Structure and other levers were the components we could manipulate directly. Many of the factors that constitute the competencies of the organization could be influenced only indirectly. This becomes visible when following the arrows in Fig. 4.4. For example, leadership cannot influence quality of care directly, but indirectly, e.g., by strengthening the motivation of the staff. 
Soon after embarking on the new venture, we used a powerful cybernetic device of organizational diagnosis and design, Stafford Beer's Viable System Model (in short "VSM"; Beer 1981, 1984, 1985). That model is extraordinary in that it claims to define not only the necessary but also sufficient structural preconditions for the viability of any organization. The model has been tested in multiple case studies (for an overview, see Schwaninger 2009; Schwaninger and Scheef 2016) and in two surveys (Crisan Tran 2006; Schwaninger and Scheef, op.cit.). After Beer's original works, other authors have made methodological contributions to facilitate the application of the VSM (e.g., Espejo et al. 1996; Hoverstadt 2008; Espejo and Reyes 2011; Pérez Ríos 2012).

To facilitate the understanding of our following account of the organization design for Oncology Carinthia, we start with a resumé of the theory of the VSM:

1. Components of the model: an organization ${ }^{9}$ is viable if, and only if, it has a set of components—which are management functions (also called "Systems") defined as follows (see Fig. 4.5):

- Component 1: the largely autonomous, basic operative units which adapt to change and optimize the ongoing business. Basic units (denoted as circles) with their respective management (square boxes) are called "primary units." Examples are a company's business units, a division, and a hospital.

- Component 2: this is the coordination function, which reduces oscillations and enhances self-regulation, for example, the reporting systems, operative planning, internal service units, standards of behavior, knowledge bases, and a good deal of communication.

- Component 3: the operative management of the organization as a whole. In a company, we would have the executive corporate management here. It provides overall direction, allocation of resources, and striving for an overall performance optimum, which often differs from the optima of the subsystems (primary units).

- Relationship Components 1-3 (vertical channel): negotiation of goals and resources - accountability, budgetary control/management by exception, and intervention (only if the cohesion of the whole organization is threatened).

- Relationship Components 1-2-3-3*: attenuation of complexity, filtration of messages coming from basic units, to inform system 3 and relieve channels 1-3. Enhances organizational cohesion.

- Component $3 *$ : the auditing channel, where the information flowing through channels 1-3 and 1-2-3, is complemented and validated via direct access to the basic units, for example, monitoring and management by walking around and informal communication as in social and cultural activities.

- Component 4: also called the intelligence function, it stands for the long-term orientation to the future and the overall environment, including exploration, modeling, and diagnosis of the organization in its environment. Here, we have organizational development, strategy (in interaction with Component 3),

\footnotetext{
${ }^{9}$ This theory also holds for other social systems, e.g., families, teams, or societies.
} 


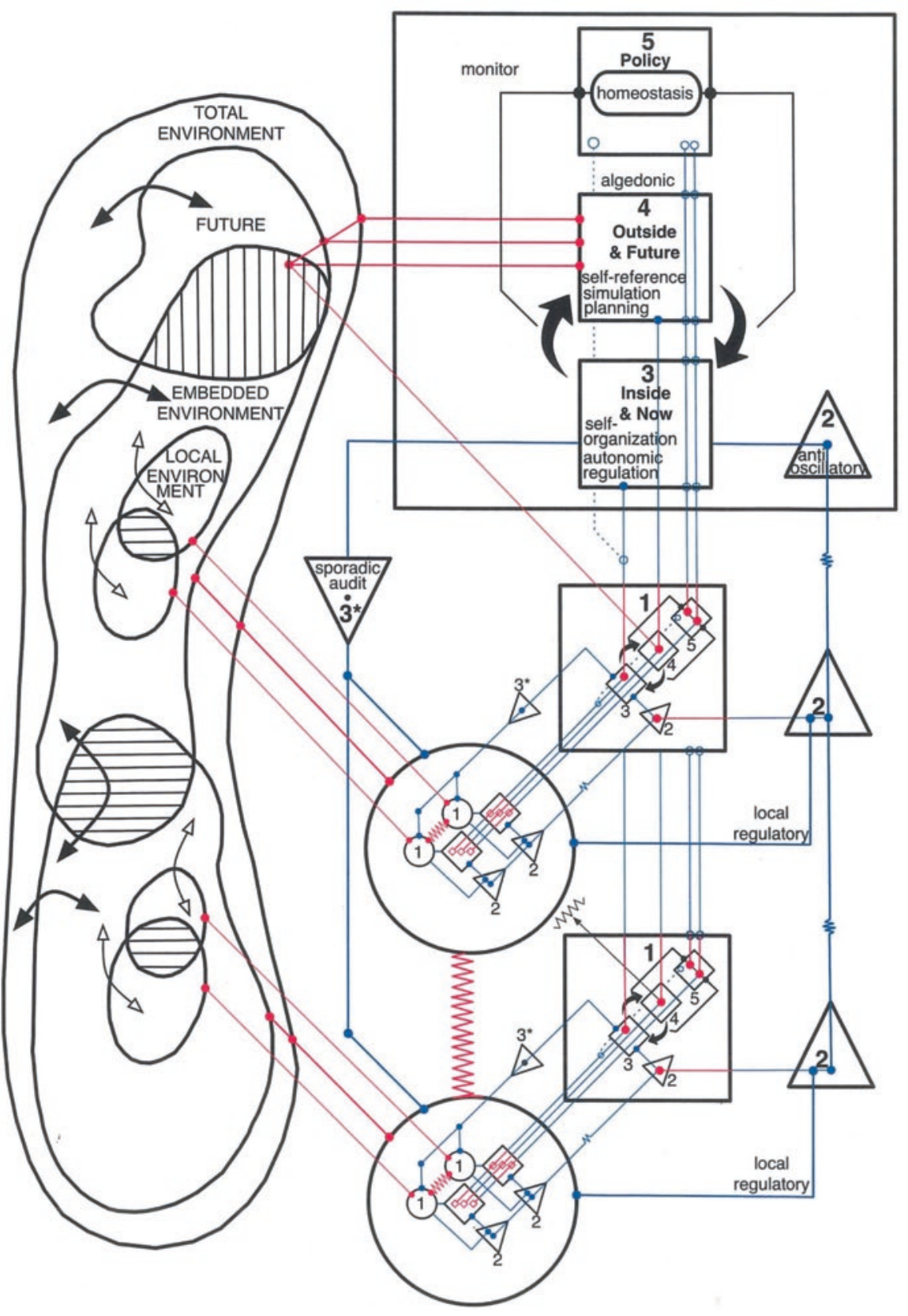

Fig. 4.5 The Viable System Model (After Beer 1985: 136) (Drawn by Ivan Ulyanov) 
research, and knowledge creation. Component 4 can trigger emergence (of new system properties) via self-reference, that is, the reflection of the system itself and, if indicated, its reframing and redesign.

- Relationship Components 3-4: interaction of short- and long-term as well as internal and external perspectives, processes of strategizing.

- Component 5: The identity as manifest in the supreme norms and values that govern the system - the ethos of the organization or normative management, also called policy function (Espejo and Reyes 2011). Striking the balance between present and future, keeping the internal and external perspectives in proportion, within a long-term or even timeless horizon. Component 5 is often (partially) codified in corporate charters, credos, value statements, etc.

- Relationship Components (3-4)-5: Moderation of the interactions of Systems 3 and 4, solution or dissolution of conflicts between the distinct logics of these Systems.

Components $1-2-3-3 *$ represent the operative system, and 2-3-4-5 the metasystem of the organization. In addition, certain alert devices can always be identified in viable systems. Beer (1985: 133) calls them "algedonic signals" (from Greek "algos" pain and "hedos" pleasure). These warning systems send signals of imminent danger directly up to Component 5, to trigger a crisis management. This component will not be analyzed further here.

2. Principle of recursion: the viability, cohesion, and self-organization of a social body depend upon these functions (Components 1-5) being recursively present at all levels of its organization.

A recursive structure comprises autonomous units within autonomous units. Moreover, a viable organization is made up of viable units, and it is itself embedded in more comprehensive viable units. Each unit, inasmuch as it is producing the organization's task, rather than servicing or supporting this, replicates-in structural terms - the totality in which it is embedded: it has all the functions outlined under (1.), to be able to manage, from start to finish, the processes for the purpose of which it exists.

This theory has strong implications. It opens a new perspective on organizational diagnosis and design: any deficiencies in this system, such as missing functions, insufficient capacity of the functions, or faulty interaction between them, impair or endanger the viability of the organization.

Accordingly, the screening of any social system in terms of the VSM brings to the surface valuable diagnostic points almost invariably (Schwaninger 2006). This is the use of the model in the diagnostic mode. On the other hand, a system's viability can be substantially enhanced if it is designed or improved according to the tenets of the VSM. This is the use of the model in the design mode.

Following the principle of recursive structure, an organization can be modeled as a cascade of viable systems embedded in more encompassing viable systems. Figure 4.5 visualizes such a structure with two levels of recursion. In the following, we will refer to four levels (Fig. 4.6). 


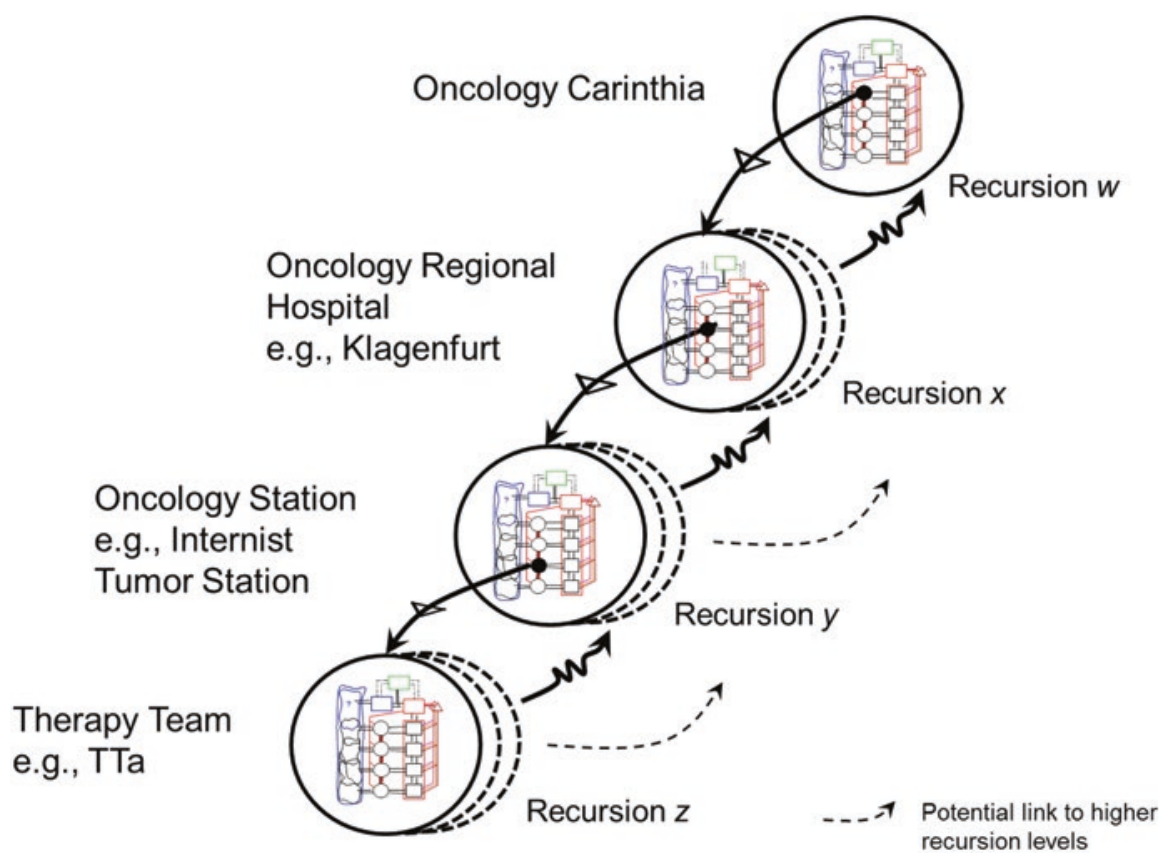

Fig. 4.6 Oncology Carinthia as a recursively structured system

The organization of the Carinthian healthcare system was the product of pragmatic structuring that found its expression in the organization charts as they can be found in most organizations today. At that time, the principle of viability was not a category used in the management discourse of that system.

We reflected on the status quo and concluded that the use of the VSM could add great value. In particular, we found the category of viability important. In addition, we were attracted by the fact that the model focuses on deep structures, as opposed to superficial structures. It is suspicious of defining sections based on perfunctory criteria and arbitrary hierarchical positions, as encountered in conventional organization practice. Organizational work with the VSM considers basic functions, relationships, and information flows. It brings the environment and the customer into the organization chart. And it builds structures for effective governance. Finally, and most important, it provides structures for the absorption of complexity for the whole organization, along the lines where that complexity arises.

Figure 4.6 visualizes the structure of the OCS as implemented within 3 years. The power of recursive organization design is visible from the diagram: the organization unfolds its capacity to absorb the environmental complexity along the fronts where it emerges. Thus, the organization is in a position to respond effectively.

We decided early on to use the VSM mainly in the design mode and have done so ever since. We also made use of it in the diagnostic mode: when you are trying to design a better organization, you better be aware of the flaws in the extant one. 
Please note that at the second level (recursion $x$-oncology regions), LKH Klagenfurt figures as a regional hospital, just as St. Veit, Villach, etc. would. This is distinct from the central oncological unit, which manages Oncology Carinthia as a whole and which is seated in that hospital as well.

A mathematical representation of the VSM can be found in Schwaninger and Klocker (2017a: Appendix).

In Table 4.2, a schema is presented which reflects a paragon for the structure of Oncology Carinthia, as designed and implemented in the 1990s for putting the strategy in place.

A system-in-focus is a unit of oncological care at any level of recursion. In other words, the overall health system is outside the influence of $\mathrm{JK}$ and will only marginally affect his area of responsibility. At the first level (recursion $w$ ), the system-infocus is the whole OCS of Carinthia. At the next recursion level $(x)$, it is the oncology in a region, e.g., Klagenfurt, Villach, or Wolfsberg, where it is centered around the central district hospital (LKH) and other local clinics. Finally, at recursion level $y$, it is an oncology station such as a tumor ambulatory or a subsystem of the internist's ward.

The table discloses a number of unconventional features of the system, as implemented in the OCS.

Basic units are the individual hospitals, but individual local oncologists also can have such a function, e.g., when they assume full responsibility for the therapy or aftercare of a patient. In the case of recursion $y$, the structure is based on teams. ${ }^{10}$ The basic unit here is not a doctor or a patient, but a connection of four components, namely, patient and family and doctor and nurse. Each one is an integral part of the therapy team, but none is only a member of that unit. Doctors and nurses are also members of other similar teams, just as the patient and the family are at the same time members of other social systems.

To highlight some of the features outlined in Table 4.2, we will mainly comment on the innovative aspects and will revert to all four recursion levels.

Component 1: A remarkable feature of the local management (Component 1) in recursion $y$ is a reversal of the conventional arrangement: the management function, i.e., the primary regulatory responsibility, is with patient and family. This corresponds to the emancipatory idea of valorizing the role of the patient, who becomes the main agent pursuing his or her health. Making this philosophy real requiresdespite this declaration about structure - that the medical and nursing staff take a different view than is common in most health systems. The patient is not a passive object to be manipulated according to expert considerations, but a force aligned with the joint quest for a successful treatment. This novel view did not emerge by itself. The champions played a crucial part in conveying the inherent values, via discourse and acting by example.

\footnotetext{
${ }^{10}$ Or systems of interaction, if we take—with Luhmann (1995)—communications as the primary components of systems.
} 


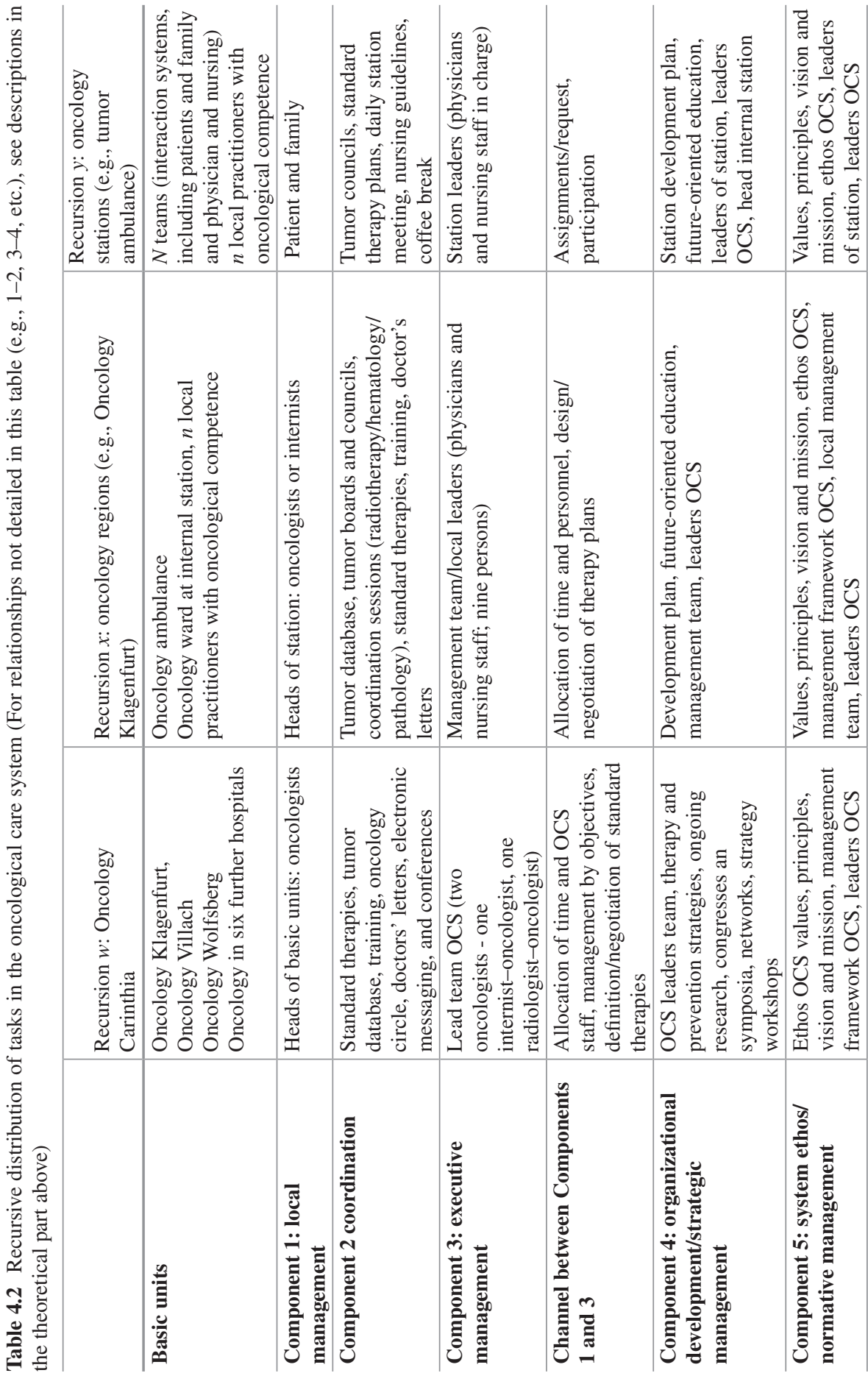


Component 2: A crucial role in coordination (Component 2) is with the tumor boards and councils (recursion $\mathrm{x}$ ). These are virtual units, ${ }^{11}$ in which the medical cases are discussed, with themes ranging from diagnosis to therapy. The cases treated by a tumor board vary in number and size; usually the therapies are defined by these boards. The tumor council is a kind of individualized tumor board (see below).

Other group initiatives are the oncology circle at recursion $w$ and the coordination meetings of radiologists, hematologists, and pathologists at recursion $x$. This principle greatly increases the efficiency of oncological care. Finally, standard therapies, training, messaging, and the doctors' letters edited by the Klagenfurt oncologists fulfil an important coordinative function.

Component 3: The executive management always involves oncologists and nursing staff. Only at the last recursion $-\mathrm{z}$, which is not elaborated in detail, in Table 4.1-the managers are patients and family. In all of these cases, shared leadership is practiced.

The connection between local and executive managements (Components 1 and 3 ), at the different recursions, makes use of the precious but very limited capacity of that vertical channel. Here is where the negotiation and control of goals as well as the allocation of resources, in addition to important feedback mechanisms and participation, take place.

Hospitals that do not have their own specialized oncologists benefit from a new service installed as a mobile unit. This is a resource of recursion $w$ deployed for the hospitals at recursion $x$. The oncologists from Klagenfurt visit the peripheral hospitals - physically or virtually ${ }^{12}$ — in a constant rhythm of 1 week (LKH Villach, LKH Wolfsberg, KH St. Veit) or 2 weeks (hospitals Spittal and Friesach), all others occurring as needed. They participate in the respective local tumor boards and also now and then, if indicated, in the local tumor ambulatories. In this way, they make their expertise available, therewith contributing to the quality of the decentralized operations. The idea here is that the doctor comes to the patient, ${ }^{13}$ rather than the patient "feeding the system." In addition, the mobile doctors are a vehicle for knowledge transfer, and indeed, the oncological know-how at the periphery has made great progress over the years. Meanwhile, the KH in St. Veit has hired its own oncologists.

Component $3 *$ : The audit channel (Component $3 *$ ) comprehends direct forms of access to the basic units, e.g., at recursion $w$, the visits to local oncology units. At recursions $x$ and $y$, the medical visits are crucial, because they give the professionals a firsthand impression of the local care situation and the individual state of the patient. Also, informal communication and cohesion-building sociocultural activities play a crucial role here at all levels.

\footnotetext{
${ }^{11}$ In many of the processes at the OCS, virtual forms of organization are adopted at the team level. Teams in the OCS are flexible in that they are formed as changing casts drawn from resource pools that exist in different locations. The resources are there, but the teams materialize in response to changing needs. They work across space, time, and organizational boundaries (Lipnack and Stamps 2000), reverting to personal contact, other communication media (mainly electronic connections), and information systems (e.g., tumor database).

${ }^{12}$ Until 2015, the journeys of the oncologists were almost entirely substituted by a teleconferencing system.

${ }^{13}$ This idea is also constitutive for the profession of barefoot doctors in India.
} 
Among the cohesion-building measures are the coffee breaks in the wards, the "onco-lunches" that gather OCS people of Klagenfurt and beyond, and the yearly oncology symposia which bring together oncologists from all over the state plus colleagues from the neighbor-state Styria. These events fulfil both coordination and auditing functions. In certain cases, they might also contribute to the intelligence function.

Component 4: This intelligence function fulfils tasks ranging into the long term and the wider environment. These tasks are, in the first place, the concern of the OCS leaders team, whose members are involved in the strategic development at all three levels of recursion: at recursion $w$ as the pioneers and masterminds and at recursions $x$ and $y$ in support roles. In the latter, it is the managers/leaders of these recursions who spearhead the design for the long-term future of their units, making up development plans and providing their staffs with education for the future. The development of therapy strategies, going hand in hand with research activities and international activities in knowledge networks, is mainly in the hands of the OCS leaders at recursion $w$.

Component 5: Finally, the system's identity, manifest in the ethos of the system, with normative management has become a systemic braid that connects members and organizational cultures of all recursion planes. Shared values, principles, vision, and mission are the same for all three recursion levels, but they need different people to enforce and exemplify them, namely, the leaders at each level.

In this structure, as shown in Table 4.2, one and the same unit often fulfils different roles with respect to the management components. For example, on recursion $w$, the management team is active in both functions, executive management (Component 3 ) and strategic management (Component 4).

The structure outlined here is a network, and so it need not be emphasized that the activities therein involve various forms of networking and communication, from formal to informal and from personal to electronic. That network is crucial for the alignment of the views of multiple purposeful actors with different goals and interests. And it enables building a shared corpus of knowledge over time. Much of that knowledge is tacit know-how (Nonaka and Takeuchi 1995), embodied in the people and teams of the organization.

In addition to the "master structure" just described, we will now delve, in more detail, into one crucial organizational feature mentioned-the teams at various levels, which are of three kinds.

First, the therapy team is the nucleus of the structure. These self-regulating teams are formed around each patient, as the primary units at recursion $z$. The care here is accomplished by the patient, his or her family, a medical doctor, and a nurse. Besides its therapeutic function, the team also engages in prevention, as far as possible. While patient and family are members of that team only, doctor and nurse are normally also part of other teams, around other patients. They are always virtually present in each of these teams, but physically present only at certain times.

Second, the tumor board at recursion $x$ is a platform that manages the continuous flow of cases to be dealt with in a given hospital. It also plays a role in the building of local knowledge. A tumor board is formed by members of different organizational 
units of different recursions ( $x$ and $y$ or even $x, y$, and $z$ ). A tumor board meets regularly to investigate the current cases under treatment. The local oncologist, if extant - and if not, a mobile oncologist from the hub-and members of specialist departments (surgery, gynecology, hematology, etc.), constitute that body. Whenever indicated, representatives of therapy teams join the board. The interaction in tumor boards is supported by the latest communication technologies, for example, if (additional) oncologists from the hub need to be involved selectively. The leadership of the board is in the hands of an oncologist.

In the central hospital at Klagenfurt (LKH) -recursion $x$-more than one tumor board has been formed. Cancer patients have their treatment across different specialized wards, gynecology and pneumology being two prominent examples. One of the oncologists moves from the LKH oncology unit to these departments, where he or she participates in visits to cancer patients, in this way forming a local tumor board, together with the local doctors in charge. This approach was later copied in the largest of the peripheral clinics, as it developed internal capacity for oncology.

Finally, the tumor council is an entity that forms itself spontaneously, if a case needs a level of attention that goes beyond the possibilities of the tumor board. The composition of these bodies varies, according to three criteria: (a) An oncologist is always present. (b) The responsible doctor ("patron") and normally the nurse in charge of the case are present. (c) Other specialists are on the team as needed. A tumor council can be summoned whenever a doctor or nurse from a specialist department needs assistance in dealing with a difficult case. In that case, an oncologist visits the respective ward, where he gathers with the local medical and nursing staff and, most important, the patient, in an on-site inspection ("ad hoc meeting"). Hence, the tumor council bundles distributed resources flexibly and effectively and is a major factor for the quality of care.

These more or less virtual teams are of a nonhierarchical ("heterarchical") type (McCulloch 1988; Schwaninger 2009). They have proven to be efficient and powerful: they enhance the quality of care, an optimal use of available resources, and growth of the body of knowledge.

Also, an increase in the cohesion of those dealing with cancer and the cooperativeness across disciplines and departments has been clearly observable. Cultural events are regularly planned to support this process. For example, once a year, a gathering of medical and nursing staff from the oncology units in Carinthia and Styria, the neighboring state, takes place in Bad Kleinkirchheim, a beautiful resort. The purpose of these events is exchanging ideas and getting informed about new developments in the field. Similar events take place, on a smaller scale, for the Carinthian staff, normally combined with a concert.

The mobile doctors as well as the tumor boards and councils are instances of decentralization. Nevertheless, certain technical resources could not be decentralized ad libitum.

The structures analyzed here represent the current state of the art. They were crucial for reaching the goals set at the beginning. Additional details about the team structures can be found in Schwaninger and Klocker (2017a). 


\subsection{Process: Phase I (The Evolution of Oncology Carinthia $(C)$ )}

Taking a broad view on the evolution of Oncology Carinthia, we can discern remarkable changes which have shaped that system.

Gradually, doctors confronted with tumor instances came to understand the advantage of close cooperation with the oncological care unit established at LKH Klagenfurt, consisting of an internist-oncologist and a radiologist-oncologist. Even those who had rejected the new approach initially, moved on to cooperative and even supportive behavior.

The concept of virtual teams was introduced. Doctors increasingly took part in tumor boards, invoked councils, and conferred with the oncology hub. The $7 \times 24$ on-call service was a major factor in building trust and gave security when a doctor took on a treatment. The concept of mobile units added a new dimension in providing high-quality care covering the whole state. The introduction of these units and the virtual team approach added enormous flexibility to the provision of service capacity.

In this way, a growing share of the departments, as well in the LKHs as at the KHs, was integrated into the OCS. Increasingly, tumor boards were established. The oncology champions were surprisingly active in research, participating in congresses and professional networks. Following the principle "as central as necessary and as decentralized as possible," intensive care patients were medicated at LKHs, under rigorous supervision of the oncological experts, while easy-to-manage cases could be treated at the clinic closest to their homes, frequently in the ambulant mode: a patient-friendly, but also a very economical way to provide oncological care. Altogether, an excellent level of care relative to the scientific state of the art was realized at Oncology Carinthia: the OCS had become an effective healthcare system.

\subsection{Results: Phase I}

Our study of Phase I demonstrates two things. At the content level, it shows the huge potential of service industries for increasing quality and productivity, even in cases of severe resource restrictions. At the context level, it makes the strength of holistic system design palpable. We were successful in conceiving Oncology Carinthia as a viable, adaptive whole, by supporting the evolution of the OCS conceptually and methodologically with systemic methods.

The first result is the organization design that has been accomplished. It is conceived around the patient as the focal point, with all features of a network organization. Patients and their families, often factored out from organizational plans, are the prime agents of the system in Oncology Carinthia. Both are crucial in the process of recovery. The central hospital and ten more clinics, as well as registered doctors, are 
part of the care network, with a pivotal oncology unit as the main knowledge hub and coordinating agent. Among the innovative features of the structure are crosssectional teams, transdisciplinary collaboration, a concept of mobile units that bring doctors to the patient rather than the other way around, and networks both inside and across the hospitals. The care process covers all phases from prevention to medical treatment to follow-up care and psychosocial accompaniment. It follows essentially a salutogenic orientation. One of the strengths of the arrangement is that both the design and management of the process are governed conceptually, with a heavy dose of theory. The implementation is an infinite learning process. In sum, an intricate, systemic path of dealing with the enormous complexity at hand has been discovered.

A second result is the stunning performance of the OCS. Despite an extreme scarcity of financial resources, both the quality and success of oncological care have been increased. The system under study has become a showcase of holistic medical treatment that has evoked sustained interest in professional circles all over Europe and beyond.

Third, Oncology Carinthia stands as an exemplar for the successful management of expertise. The influence of organizing and managing in general on the evolution of the system has become tangible. Yet it has not provoked the likely conflict between medical and managerial logics, which often deteriorates the qualification of professionals (Boos and Mitterer 2014). Instead, it brought to fruition a constructive force for the system's viability. The reason is twofold: On the one hand, management in this case has never become a pathologically autopoietic system (Beer 1979). On the contrary, it has been instrumental in pursuing the purpose of the whole system-in-focus: a statewide, excellent level of care, enabled by transdisciplinary collaboration. On the other hand here, management, including leadership, was radically decentralized and, furthermore, was integrated or "dissolved" into heterarchical, mobile, and virtual structures. This has entailed a powerful rise in the repertoires of behavior ("variety") at all levels of the organization, enabling multiple agents to cope with complexity forcefully. Oncology Carinthia has become more agile in both time and space.

The concerns and needs raised initially (Sects. 3.1, 3.2, and 3.3) were met fully by the organization developed within roughly 10 years (1985-1995): by then the new system was running at "full steam." In fact, the outcomes exceeded all expectations. A major factor was the substantial freedom granted to the champions by the state health authority of Carinthia.

Some of the results were unexpected, for example, the evidence that (a) organizational structures can be nimble and robust at the same time and (b) a more complex structure is not necessarily more expensive; it can even be more economical.

The results referred to here are not an endpoint. On the contrary, the OCS team has seen itself confronted with new challenges along the way. Over time, competencies evolved and structures had to develop as well. Transformations of structure took place for meeting new needs, for example, the establishment of two transdisciplinary units, a central ambulance, and an oncological ward for special cases, as well as the foundation of an intensive care unit for oncology. 


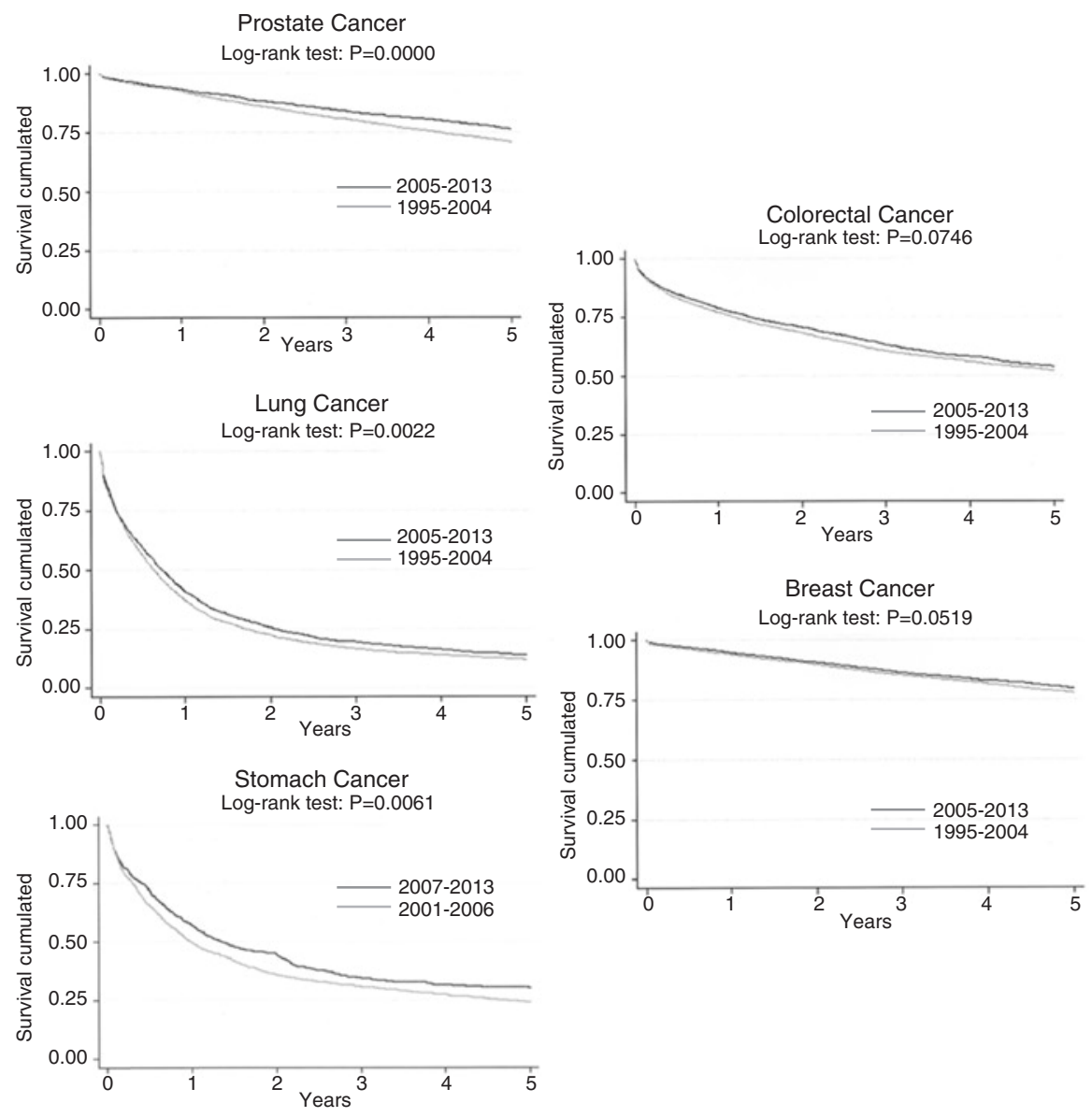

Fig. 4.7 Survival rates for main entities of cancer in Carinthia 1995-2013

We were not dealing with a machine, but with a social system. Hence, the design approach was both formal and informal. The results were emergent. Culture and structure were always "in progress," adapting and evolving.

We have claimed that the OCS Carinthia has become a highly effective system of healthcare. Can this claim be upheld in view of empirical data?

We consulted the "Tumorregister Kärnten" (Tumor Database Carinthia) in Klagenfurt, to examine if there was any evidence of medicinal effects of the OCS, over the period covered by our study. We received long-term data series on the evolution of 5-year survival rates, in Carinthia, for the five main entities of cancer indications (Fig. 4.7). Five-year survival rates are the most important indicator of effectiveness in oncological care (Ziegler et al. 2007).

The axes in the five graphs show the period of survival after the treatment (from 1 to 5 years) and the percentage of patients surviving (1.00 being 100\%). 
Each graph shows two curves, one for the period 1995-2004 and the other for 2005-2013 (in case of stomach cancer for 2001-2006 and 2007-2013). ${ }^{14}$ The graphs tell us two things:

(a) For prostate, lung, and stomach cancer (Fig. 4.7, left), there is a highly significant improvement of the survival rates from the first to the second period. The respective $\mathrm{p}$-values of the log-rank test are $p<0.0001$ for the first indication and $p<0.01$ for the second and third indications. ${ }^{15}$

(b) For colorectal cancer and breast cancer (Fig. 4.7, right), there is a trend indicating improvement, even though the level of significance is less impressive. Here, $p$-values are at $p<0.1$.

This analysis testifies success and that success could only be achieved through high quality of care. The numbers underpin the claim made above: the OCS became a highly effective healthcare organization.

\subsection{Conclusions: Phase I}

What can be learnt from this case? Many insights and lessons have emerged throughout the sections of this chapter. In closing, we shall try to condense our findings in a brief resumé, which cannot lay claim to being a full-fledged theory, being instead a set of crucial aspects conducive to ongoing learning. As these aspects have been tried and tested extensively over a long period, we dare to switch, at times, from the descriptive mode to "normative" propositions, i.e., suggestions of how things should be done:

(a) Ethos: The focus should be on the patient, with his or her family included. This means placing the patients and their quality of life at the center. Not only at the center but also in command: the patient is the authority responsible for his or her health. For the doctors, nurses, and other employees, a culture of highest professional values, including unconditional commitment to patients, is the imperative to be adhered to. The principle of excellent care must pervade all activities. Goals have to be high, and leaders need to energize the organization to attain them.

(b) Systemic approach: Systemic thinking is a way of dealing competently with complex wholes. It enables systemic design for better organizations. The

${ }^{14}$ Initial values n (number of patients):

Prostate: 3828 (2005), 3819 (2005)

Lung: 2734 (1995), 2908 (2005)

Stomach: 783 (2001), 848 (2007)

Colorectal: 3259 (1995), 2953 (2005)

Breast: 3579 (1995), 3760 (2005)

${ }^{15}$ According to the null hypothesis, there is no difference between the two survival curves. Given the results of the log-rank test, the null hypothesis is refuted. 
proposed thinking at the levels of both content and context forms a braid that enables a systemic process reaching from modeling to assessment to design to change. Unorthodox thinking, as our case showed, can produce management innovations that, although unwelcome at the beginning, go on to breed (unexpected) positive results and are adopted by the organization. To initiate and manage these innovations, powerful change agents are a sine qua non. ${ }^{16}$

(c) Theory and practice: Practitioners are often theory-averse. Therefore, we pursued an unorthodox path, operating on a strong theoretical (and methodological) orientation, combining it with pragmatic, flexible implementation and-most importantly - with enduring dedication to the issues of health. This alternative path proved to be at the core of the success of Oncology Carinthia. The combination of theoretical-conceptually driven design and reflexive, committed practice is mandatory for dealing effectively with complex organizational issues in a social system.

(d) Methodology: We have tried to catalyze the dialectics of strategy and organization, proposing two methodologies (SD and VSM) that facilitate dealing with the complex issues under study. These are not the only methodologies available, but they appear to be mature devices on which one can rely in the face of complexity. And they are complementary. Much as with engineering, the methods chosen rely on the cyclic pair of reasoning and experimentation (Golden 2017).

(e) Holistic organization design: The systemic approach provides highly effective heuristic devices and frameworks (e.g., VSM) for enhancing the viability and adaptiveness of organizations. Holistic design combines decentralization and centralization, as well as information flows from inside-out and outside-in, which is a better model than top-down and bottom-up. Structures can be nimble and robust at the same time, and a complex structure can be even more economical than a simplistic one. The systemic approach based on VSM and other cybernetics-based structural models not discussed here ${ }^{17}$ is very potent in putting networks and virtual organizations in place, which absorb complexity pervasively. This proves to be the case here in an organization that is above all humanistic.

The main implication of our study is that these insights and teachings can also deliver value to other protagonists and "engineers" of healthcare systems. Even more, we trust that the organizational concepts discussed herein can convey lessons to organizers in any industry, showing them new paths of coping with complexity. As far as management scientists and students are concerned, the

\footnotetext{
${ }^{16}$ In the case under study, both an internal and external change agent were active and in harmony. This may have been an important prerequisite for the successful performance of Oncology Carinthia (Birkinshaw 2008).

${ }^{17}$ For example, Team Syntegrity, a systemic protocol for the interaction in large groups (Beer 1994; Schwaninger 2003)
} 
systemic approach — framework and methodology_documented in this reflexive case might potentially enhance their professional knowledge and repertoire.

All of the aspects synthesized above are becoming ever more important, as the complexity of systems grows. The immediate results secured by organizations are less important than their viability in the long run. We have relied on the VSM to structure the OCS because that model defines not only the necessary but also the sufficient preconditions for such viability. Therefore, the design we have proposed and implemented is not only successful, but it also has great potential for some time to come.

There are limitations to both the case and this chapter. As far as the case is concerned, even though the OCS has bred remarkable results as we have reported, nonetheless, Oncology Carinthia is not perfect; there is room for further improvement. For example, to date, our successes at the preventive end are below our initial expectations.

As far as this report about Phase I is concerned, its chief limitation inheres in the difficulty of capturing the richness of 25 years of experience in a short document. For example, we cannot account for all the scenarios, the various what-ifs, and sowhats that emerged in the process. Also, little has been said about the relationships between Oncology Carinthia and its external stakeholders, etc. Although we could write a book, still a concise piece of work like this is more digestible.

\section{Phase II: 2011-2015}

The outcomes of Phase I documented above exceeded all expectations. A major factor of success was the substantial autonomy granted to the leaders of the OCS by the state health authority.

However, 25 years after the foundation of the oncological care unit, clouds appeared on the bright skies under which the OCS had sailed for such a long time. In 2011, the administration of the central hospital announced that it would cut the budgets of all departments, “... to improve the economic situation.” The leaders of the OCS made a rough estimate: such a cut would reduce their financial resources available by roughly Euro 210,000 for the year and 570 per day. For a small unit, this would be a painful cut. The oncologists understood that such a move would profoundly affect the whole operation of the OCS.

\subsection{Content: Phase II (Simulation Model (M))}

To analyze the situation more closely, a simulation model was built cooperatively: the oncologists, mainly the second author (JK), contributed the substantive knowledge about the issues under study, while the first author (MS) furnished modeling and simulation know-how. The purpose of the model was to anticipate what the 


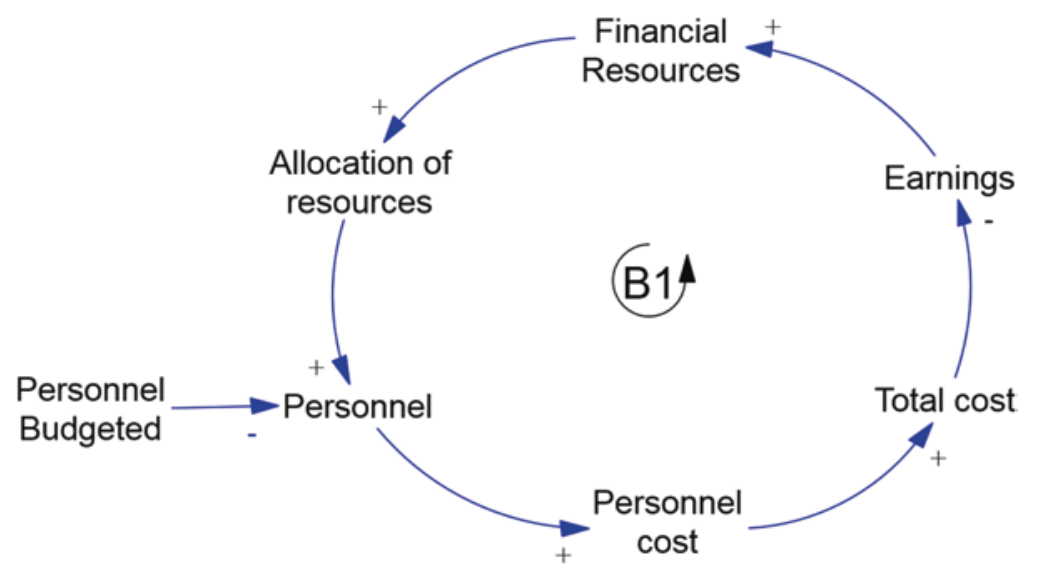

Fig. 4.8 Finance personnel loop

implications of the announced cut in the budget would be. The users of the model would be the oncologists, but the results of the simulations were meant to be presented to the administrators of the hospital.

\subsubsection{Qualitative Model Components}

The dynamic hypothesis of the oncologists - to be formulated in the next sectionwas based on a qualitative analysis, hereafter presented in Figs. 4.8, 4.9, 4.10, 4.11, and 4.12. The form we are using is that of causal loop diagrams, as already in Sect. 4.1. There, we took a top-down procedure, starting with a complete qualitative network (Fig. 4.3). Here, we start with individual qualitative loops, which are then synthesized into a quantitative simulation model.

The finance personnel loop (Fig. 4.8) shows a connection that is straightforward: the allocation of financial resources enables hiring people therewith increasing the workforce. The larger the workforce, the higher the cost, which in turn decreases earnings and financial resources available. This is a balancing loop (B1). Balancing loops are normally controlled by a goal or limiting factor. In this case, the personnel budgeted delimits the quantity of personnel.

Compared to the first loop, the second one (Fig. 4.9) highlights a countervailing relationship: the larger the workforce, the greater the experience and knowledge extant in the organization. The more experienced people are, the less susceptible to stress they become. Even so, stress is a proxy for a working climate that enhances the number of exits, which reduce personnel. This experience-stress loop is selfreinforcing, leading either to a virtuous or a vicious cycle.

Figure 4.10 features two loops that show the causes and implications of both stress and quality of care (R2 and R3). A lack of personnel leads to overload and stress, which is a major factor that jeopardizes quality of care. The success of care 
Fig. 4.9 Experience stress loop

Fig. 4.10 Stress quality loops
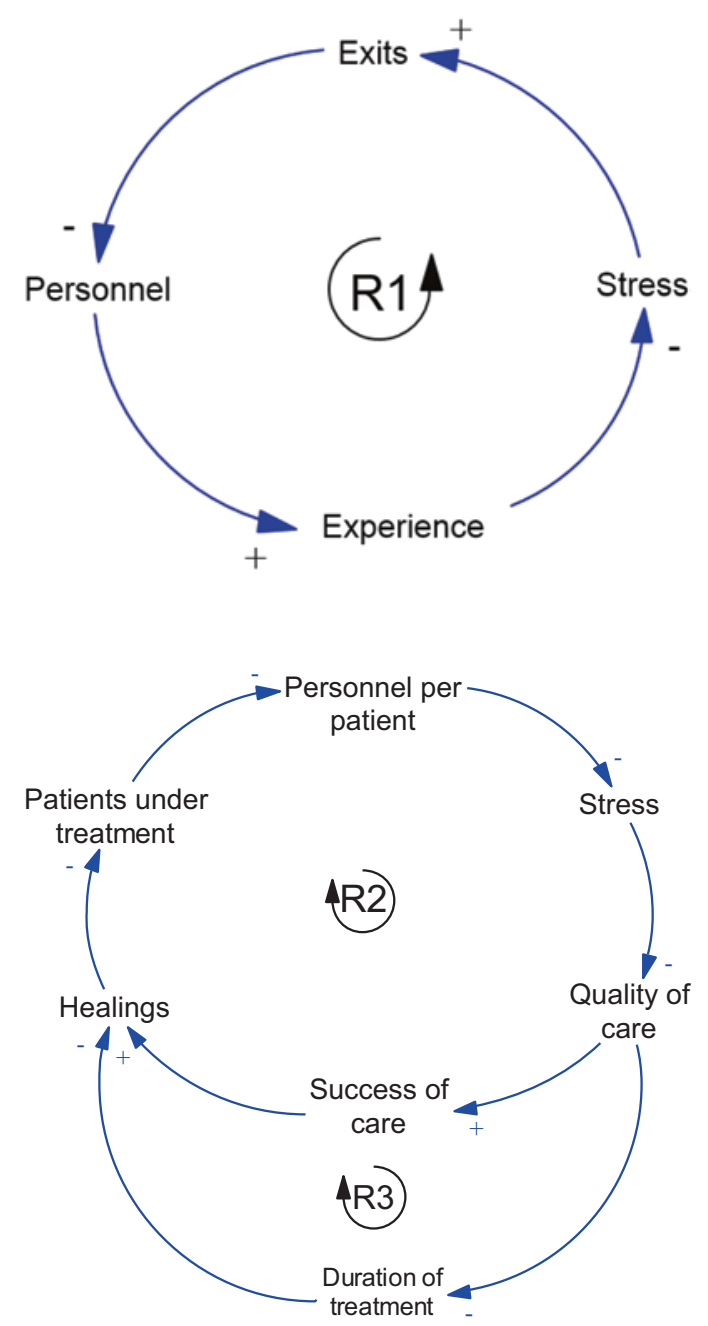

and the resulting number of cures alleviate the load of patients under treatment, consequently improving the personnel-patients ratio and alleviating stress. Lower stress implies higher quality of care and then higher success of care. As the outer loop shows, quality of care-due to better dedication of staff and superior organization-reduces the duration of treatment, which affects the number of cures: shorter duration of treatment results in more healings. Both loops are of the reinforcing type.

The goal adjustment loop (B2) in Fig. 4.11 again features a structure underlying a balancing behavior. The already discussed links from personnel to personnel intensity (personnel per patient) to quality of care, success of care (measured by remission rate), and patients under treatment are brought together here with a crucial balancing factor, namely, the adjustment to the goal for headcount (desired 


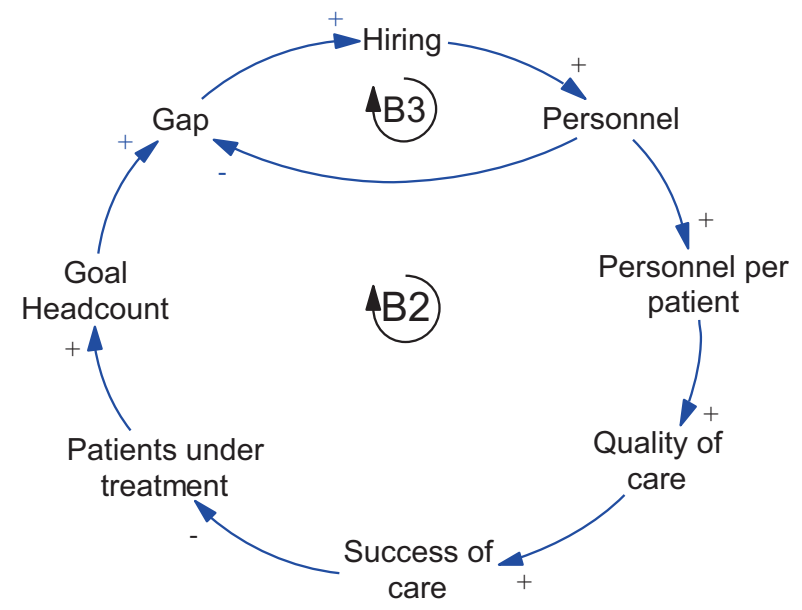

Fig. 4.11 Goal adjustment loop

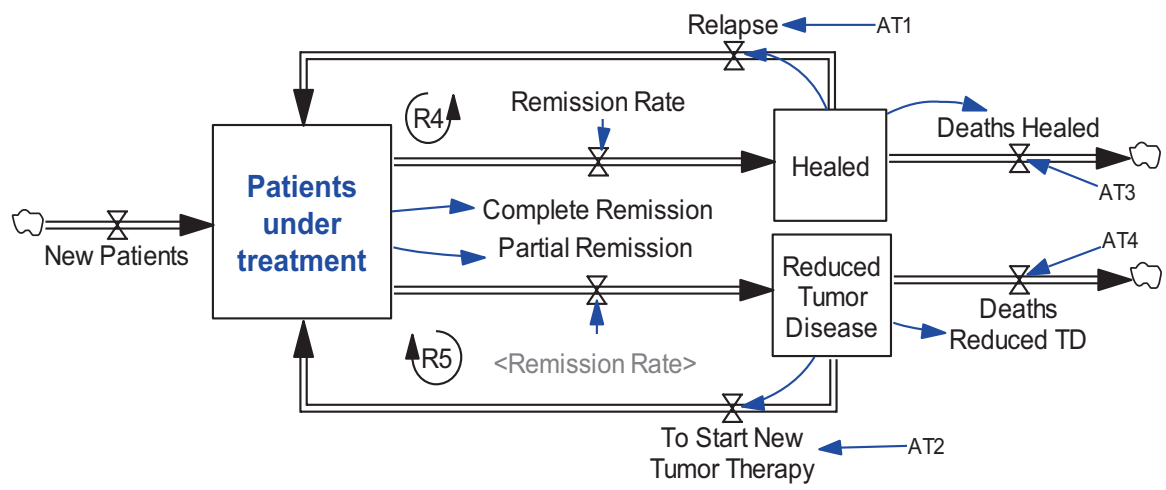

Fig. 4.12 Healing process loops

headcount). A staff target ("goal headcount") higher than the actual headcount ("personnel") induces hiring activities, which enhance workforce size, etc. (Loop B3). We may call this a "solution loop" because it would in theory lead to a better response to increasing patient loads.

For the next schema (Fig. 4.12), we have chosen the form of a stock and flow diagram instead of a causal loop diagram, in order to introduce the distinction between stocks and flows. This kind of diagram will then be used for the visualization of the quantitative simulation model.

The diagram is made up of two self-reinforcing loops that represent the healing process (Fig. 4.12). The variables in boxes are stocks that can either build up or be depleted. The variables pictured as valves are flows that increase or decrease the stocks. In this diagram, all relationships between flows and stocks are of the "increase" 
Fig. 4.13 Dynamic hypothesis of an erosion of the quality of care

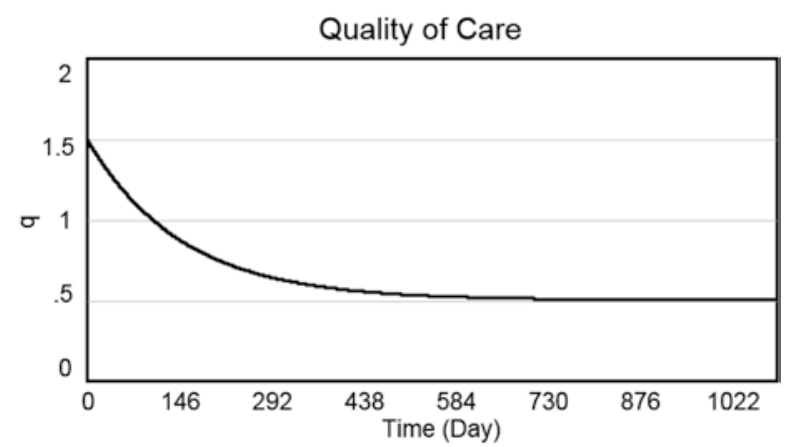

type. The two loops demonstrate how the volume of patients under treatment builds up: in the upper loop (R4) more patients under treatment induce more healings (complete remission), triggered by a remission rate, i.e., the percentage of patients healed. That rate increases the number of healed persons (without tumor disease). The larger the stock of people without tumor disease, the more relapses there will be and therewith more patients under treatment. All other aspects being equal, the number of patients under treatment tends to increase. This amounts to an avalanche effect.

If we were to expand our perspective, we would recognize that there are influences from outside: patients under treatment would grow also as a function of new patients, and the healed persons would decrease slowly as a function of deaths (see the complete model in the Appendix). The lower loop (R5) replicates the logic of loop (R 4), for the fraction of partial healings.

\subsubsection{Dynamic Hypothesis}

Based on these causal loops, the dynamic hypothesis of the oncologists was as follows: if the budget is cut, this will entail an increasing overload and stress of the personnel in the OCS and therewith lead to a decay in the quality of care, with a growing load of patients to be treated. The reference mode is pictured in Fig. 4.13.

\subsubsection{Quantitative Model}

We have taken all the loops outlined above as building blocks and synthesized them into a quantitative simulation model. The overall picture of that model, in the form of a stock and flow diagram, is shown in the Appendix. We have abstained from introducing a stock for backlog, assuming that incoming patients had to be treated by all means.

The model is made up of equations, mostly differential equations. It covers a period of 3 years, from January 1, 2013 to December 31, 2015. It runs over 1095 days. The equations of the model are documented elsewhere (Schwaninger and Klocker 2017b). 


\subsubsection{Scenarios and Policies}

We are now deploying the simulation model (see Appendix), first to establish a number of scenarios that ascertain first, where the OCS was going under constant conditions ("base scenario"), and second, what the consequences of the announced budget cut would be ("budget cuts").

In Fig. 4.14, the simulation results for these two scenarios are compared; the trajectories of ten variables are plotted. They show nonlinear patterns of behavior throughout.

\section{Base Scenario (I)}

In the base scenario (no change of conditions), the number of patients under treatment and capacity use would grow along a sigmoid curve, with gradual changes in the first year. The use of capacity (not in the diagram), which is already loaded fully at the outset, becomes more and more stressed. The number of complete remissions shows strong growth as well, albeit along a decreasing slope. The dampening effect here is in the decrease of personnel. Why should the staff shrink? The personnel budgeted is constant. Hence, the answer lies in the exits, which are triggered by the growth of stress due to overload of the personnel. In addition, the greater turnover of staff, with a lag, leads to a loss of experience per staff member, starting after 19 months. Experience in its own right is a factor that dampens stress. As experience increases, stress first grows only moderately, but the ensuing institutional loss of experience leads to more growth of stress. As a consequence, the quality of care, which is the main indicator for patients' quality of life, erodes markedly over the whole period. The duration of treatments increases continually, as a function of the drop in quality of care. Finally, one might think that the earnings would grow as the number of patients rises. However, as patients stay under treatment longer, the cost of care (cost per patient) increases as well, while the income stagnates. Hence, by month 17 , the earnings move into a sustained negative status. Cumulated earnings become definitely negative in month 26 .

Altogether, the OCS is in a situation of relative strength at the outset. However, there are signals of a gradual weakening of that position. Over the first 12-17 months, personnel, stress, and earnings change little, while experience even grows significantly. However, a less favorable situation is incipient, as stress builds up and the quality of care loses ground. Overload creeps into the system and causes stress, which jeopardizes the quality of care.

\section{Budget Cuts (II)}

The budget cuts scenario examines the implications of the measures announced by the hospital administration. Two variants are analyzed: (a) a continuous cut of daily budgets by $15 \%$ over the whole simulation period and (b) a cut of the daily budgets 

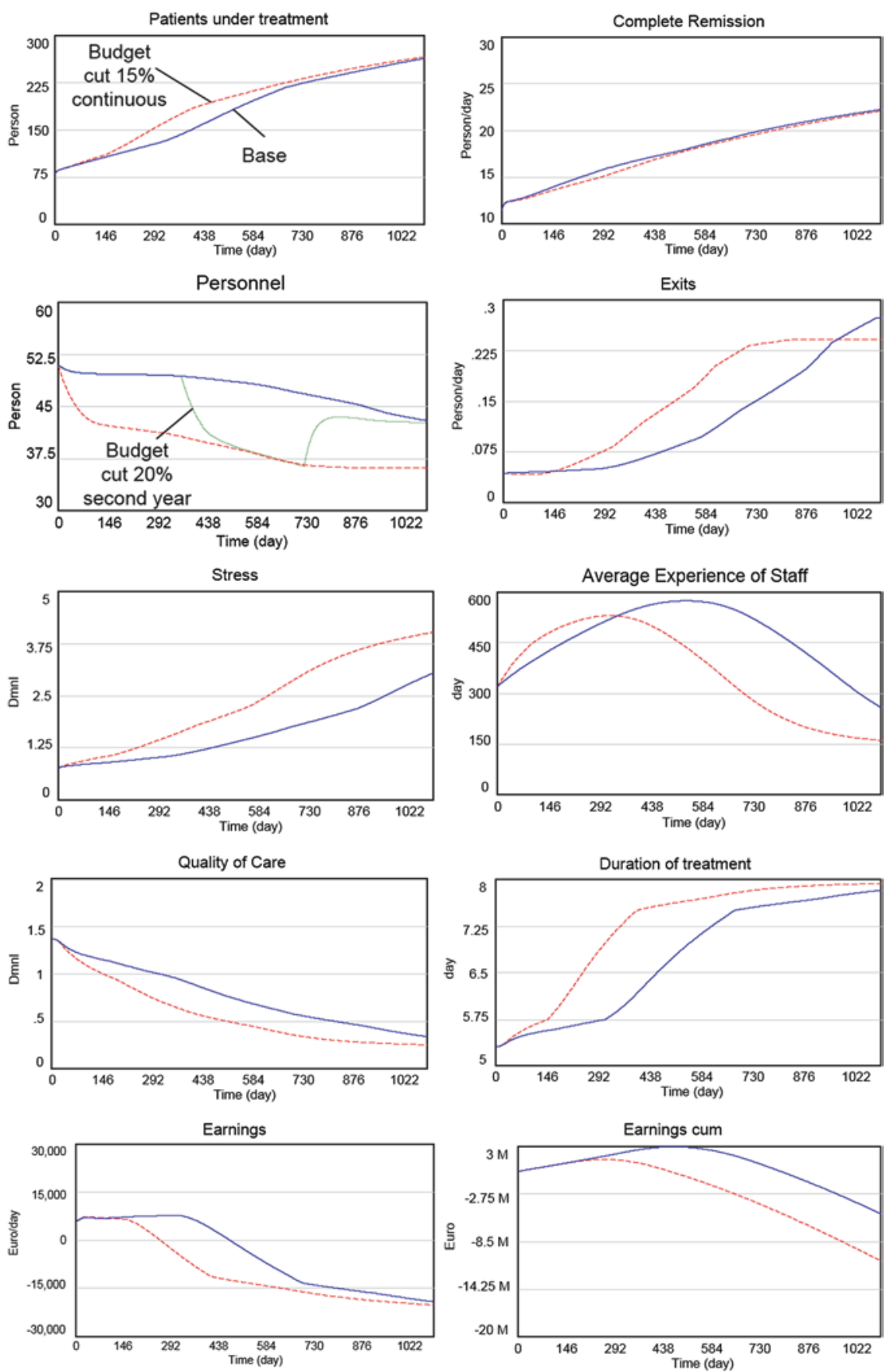

Fig. 4.14 Budget cut scenario. Base run (no budget cut); budget cut 15\%, continuous; budget cut $20 \%$, only second year 
by $20 \%$, over 12 months (days 366-731) only. We make the simplifying assumption that all budget cuts are applicable to staff expenses only, leading to decreases in the workforce.

The graphs in Fig. 4.14 show that the personnel drops substantially as a consequence of the budget cut. ${ }^{18}$ That leads to counterintuitive behavior of the system under study. The number of patients under treatment and the capacity used do not behave as in the base scenario, but instead they increase to precarious levels. In a nutshell, this can be explained as follows: the decrease of personnel intensity induces overload and more stress, which accelerates the exit of employees and leads to a lower quality of care. The consequence is a longer duration of treatments, i.e., people stay in hospital longer. Another remarkable feature is that the number of complete remissions hardly decreases with the budget cuts. What recedes, and dramatically, is the quality of care-the cornerstone and lead indicator of a healthcare system: growing stress and falling staff experience occur at the price of unsatisfactory treatment of patients. This unexpected outcome makes visible a trade-off whose importance cannot be overestimated: quantity versus quality.

A second and even more surprising result concerns the economic dimension. The budget cuts appear to be successful in that fewer resources need to be allocated. However, that impression is misleading. It turns out that the flow of earnings, which is positive in the base scenario for 15 months, becomes negative already after 8 months, in the budget cut scenario. With -10.8 Mio Euros, the cumulated earnings are negative-twice the amount of the base scenario. In other words, not even the economic quantities respond to the interventions in a desirable way.

Much of the behavior of the model is counterintuitive from the viewpoint of the managers, while it makes sense from the stance of the medical staff. Even so, the working of the "mechanisms" just analyzed was fully understood by the doctors only in hindsight, when they saw the results of the simulations and had observable light bulb moments.

A comparison of simulation outcome with the assumptions made in the dynamic hypothesis, in line with the reference mode for quality of care (Sect. 3.2), is presented in Fig. 4.15.

\subsubsection{Policies}

Among possible sensitivity analyses, we only present one, to answer the question: could changes in the daily budget bring about positive cumulated earnings? The upper graph in Fig. 4.16 shows the results of 200 runs for a parameter variation of "budget change" from zero to 1000 Euro a day. The cumulated earnings are plotted with the shades of gray symbolizing the different confidence levels, i.e., the respective percentages of the amount of total runs. The share of runs in the diagram above the axis at Earnings $s^{\text {cum }}=0$ indicates that positive cumulated earnings can, in

\footnotetext{
${ }^{18}$ That applies, as well, to the temporary budget cut for 1 year's time, but there the headcount rebounds as the budget goes back to normal.
} 
Fig. 4.15 Comparison of simulation outcome for personnel with reference mode (assumption: budget cut of $15 \%)$

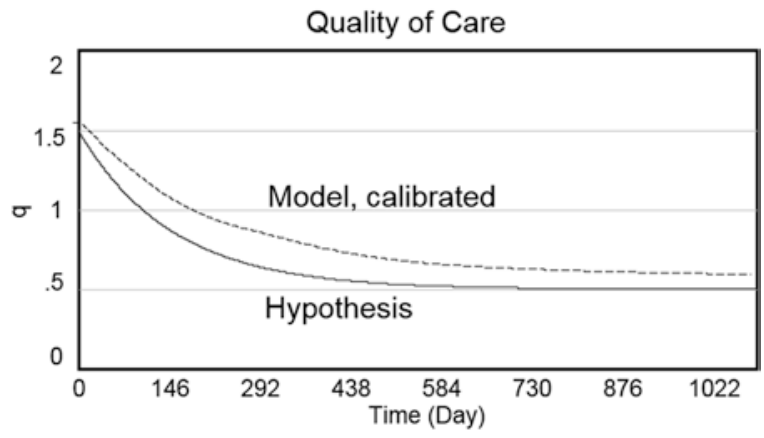

principle, be obtained by an expansion of the budget. The lower diagram specifies that for this aim, a minimum increase of the budget by 600 Euros a day is necessary. This would imply support from the public sector, but that support would be compensated through negative earnings over time.

Another parameter examined is the hiring policy. Our sensitivity analysis shows that hiring people with more professional experience entails positive consequences throughout: quality of care can be maintained, stress is mitigated, duration of treatment is hardly increased, and earnings remain positive (Fig. 4.17), etc. The advantages of this policy are obvious, but it is difficult to implement it, as the market for hospital staff in the region is dried out.

Further scenarios were run to explore different policies, namely, changes in resource allocation. In addition, scenarios and sensitivity analyses for showing the implications of different levels of inflows of new patients were elaborated. Policies to mitigate capacity shortages were examined as well. We abstain from presenting a detailed log of these additional simulations undertaken, to avoid stretching this chapter beyond purpose.

\subsubsection{Model Validation}

The processes of modeling, i.e., building the model, and validation, i.e., the effort to ensure quality of and confidence in the models (Forrester and Senge 1980; Barlas 1996; 2000a, b; Schwaninger and Groesser 2011), were simultaneous and intertwined.

The model was validated thoroughly in accordance with the principles and methods developed in the system dynamics community. For the qualitative model, a thorough dialogue took place between members of the OCS and the modeler, in the sense of structural validation, e.g., with structure and parameter examinations, boundary tests, and dimensional consistency checks.

The first version of the quantitative model was built in 2012, for a first examination of the consequences of a budget cut. The results were presented at a gathering 

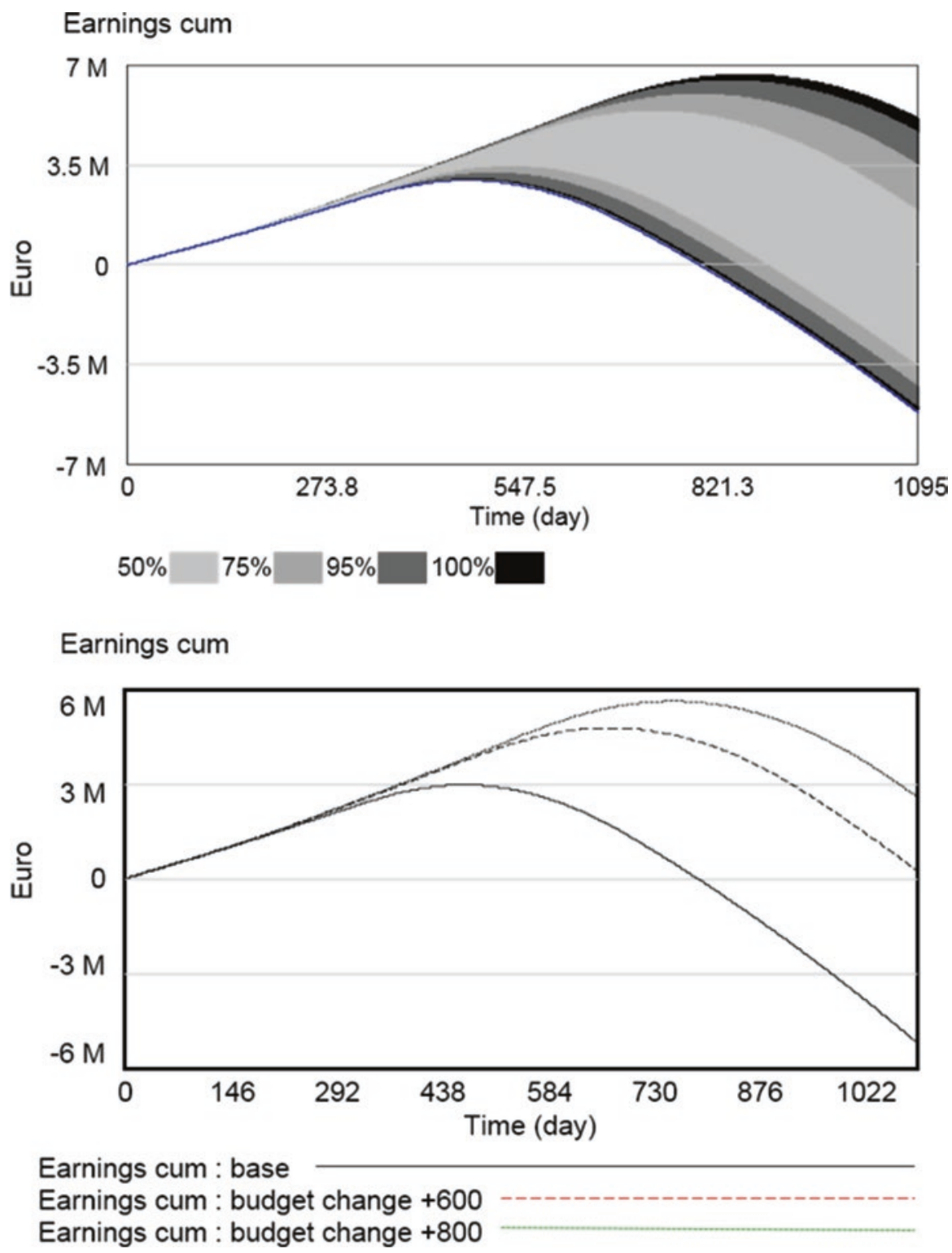

Fig. 4.16 Sensitivity analysis-impact of budget change on cumulative earnings. 200 runs. The shades of gray show the results in bandwidths, each shade standing for a certain percentage of the total number of runs

of the OCS staff, including employees from all levels, leading medical executives to doctors and nurses. In a nutshell, it became clear to them that a budget cut in the range of 10-20\% would be counterproductive. Even so, at that stage, a budget cut of $15 \%$ was introduced by the administrators. 


\section{Earnings}

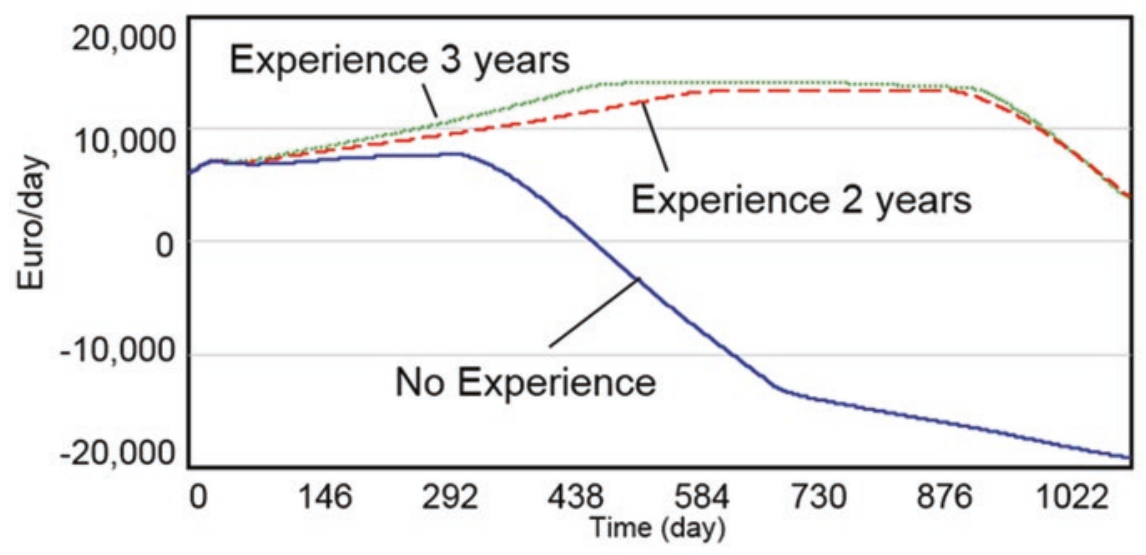

Earnings cum

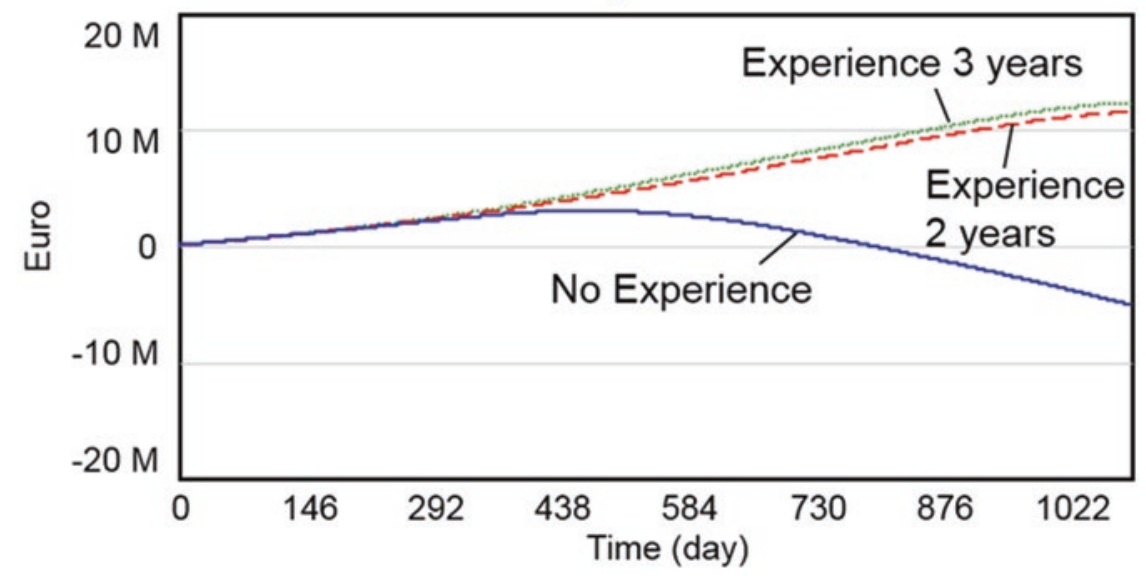

Fig. 4.17 Sensitivity analysis—impact of experience of persons hired on earnings and cumulated earnings

The first version of the model showed the same features and produced roughly the same results as the second, calibrated version, even though it had not been submitted to a validation process as rigorous as the later version. That second version was carried out in early 2016, to enable an analysis in hindsight. It sought to determine if the model anticipated the development of the OCS adequately and to what degree.

The validation of the quantitative model was essentially carried out by the first author as the external member and the second author as the internal member of the 
team. These validation tests were of the indirect structural type, involving mainly sensitivity analyses, extreme conditions tests, dimensional consistency and integration error tests, and the mass balance check (Dangerfield 2014). All of these were passed.

Behavior reproduction tests were first carried out by qualitative expert judgment, in relation to all outcome variables, with numerous parameter variations. In addition to these tests of "face validity," more rigorous approaches were taken-surprise tests, loop knockout tests, etc. System improvement tests were also carried out and will be documented in the section on policies. ${ }^{19}$ As usual, the validation procedure involved several iterations.

In early 2016, as historical data became available, the model was submitted to behavior reproduction tests, in the next round of validation experiments. The authors were supported by hospital staff, who provided essential data. The quantitative model was calibrated on the accessible data series about personnel headcount and patient healings (complete and partial remissions).

In Fig. 4.18, the simulation outcomes of the calibrated model are compared with the historical data ("real") obtained from the OCS.

We are documenting the respective measures of fit in Table 4.3.

The correlation between simulated and historical data is close to the maximum of $100 \%$. The mean squared error, i.e., the averaged squares of the differences between observed and simulated data, with 0.06 , is very low. With a half percent, the mean absolute percentage error is very small as well. The Theil statistic explains the three components of the mean squared error $\left(U_{\mathrm{m}}+U_{\mathrm{s}}+U_{\mathrm{c}}=1\right)$. The simulation result shows no systematic bias caused by the differences in the dataset's mean value that would result in an overall upward or downward shift of the curve $\left(U_{\mathrm{m}}\right)$. The simulated curve closely depicts the variation of historical data with almost no difference in the magnitude of fluctuations $\left(U_{\mathrm{s}}\right)$. The differences between the historical and the simulated datasets can be attributed largely to unsystematic point-bypoint mismatch/discrepancy/noise $\left(U_{\mathrm{c}}\right){ }^{20}$ The analysis of the mean squared error confirms that the model captures the overall trend in the historical behavior.

According to established standards, the fit obtained is very high. Hence, strong confidence in the model is justified.

\subsubsection{Discussion and Implications}

Our simulations support the dynamic hypothesis formulated earlier: the assumption was that a budget cut would lead to an increasing overload and stress of the OCS personnel and therewith to a decay in the quality of care, with a growing load of patients to be treated.

\footnotetext{
${ }^{19}$ For more details about the validation tests, see Schwaninger and Klocker (2017b).

${ }^{20}$ For the uncertainty statistics used here, see the original in Theil 1966 and the application to system dynamics in Sterman 1984.
} 


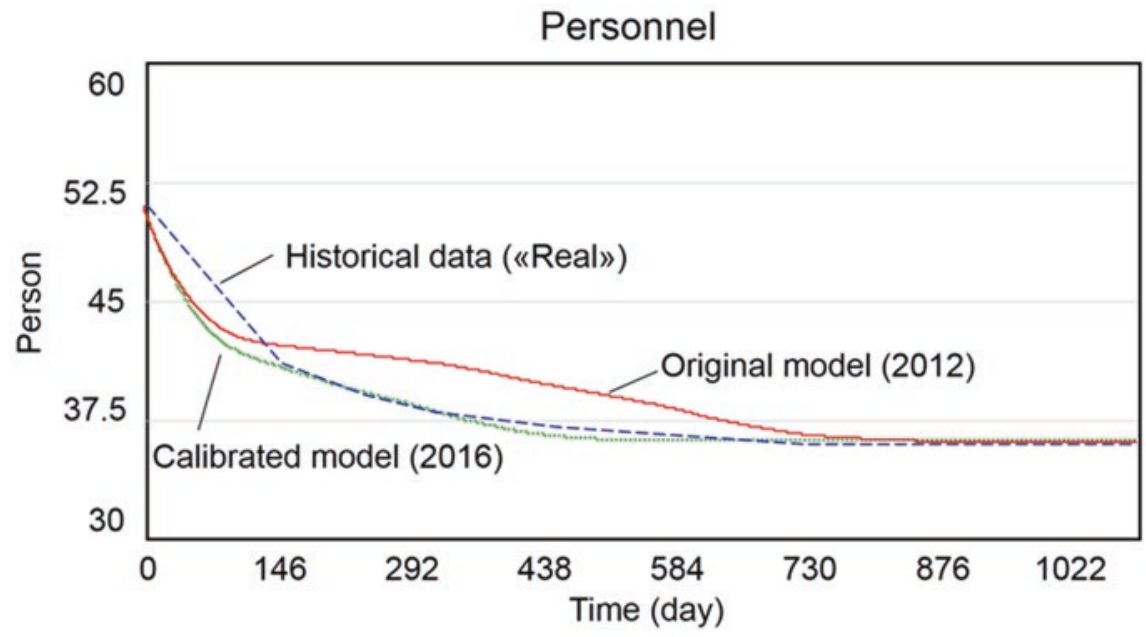

Complete Remission

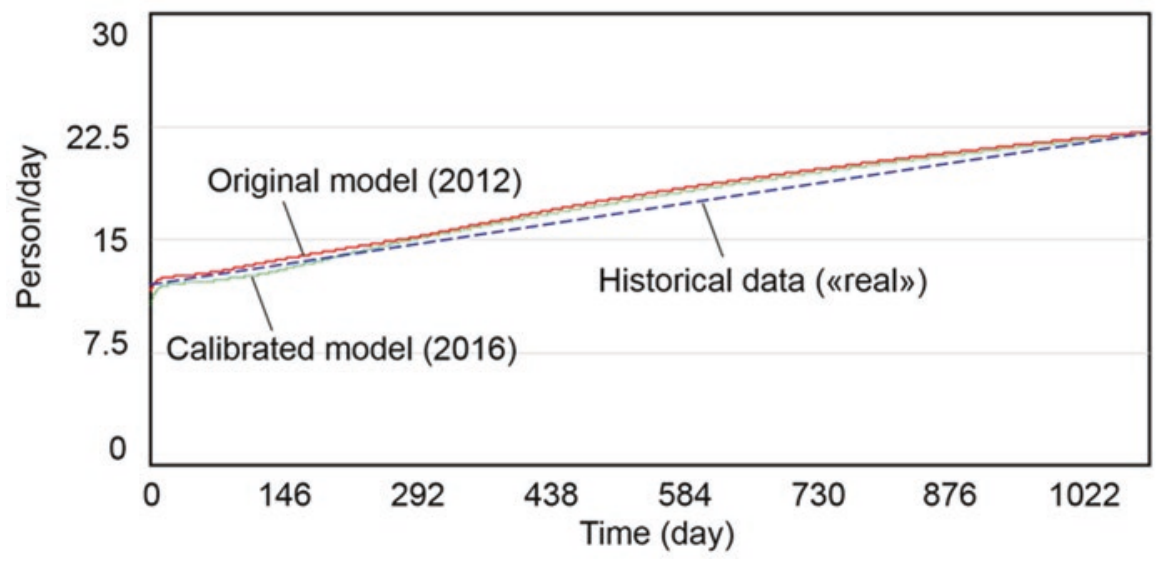

Fig. 4.18 Behavior reproduction of the model

Table 4.3 Measures of fit with historical data of the simulations (Fig. 4.18)

\begin{tabular}{l|l|l}
\hline Indicator & Size & Meaning \\
\hline$R^{2}$ & 0.997425 & Coefficient of determination \\
\hline MSE & 0.061587 & Mean squared error \\
\hline MAPE & 0.520675 & $\begin{array}{l}\text { Mean absolute percentage } \\
\text { error }\end{array}$ \\
\hline$U_{\mathrm{m}}$ & $1.41 \mathrm{E}-07$ & Mean difference \\
\hline$U_{\mathrm{s}}$ & 0.000491 & Variation \\
\hline$U_{\mathrm{c}}$ & 0.999509 & Covariation \\
\hline
\end{tabular}


Fig. 4.19 High-level diagram of three mutually reinforcing factors leading to crisis

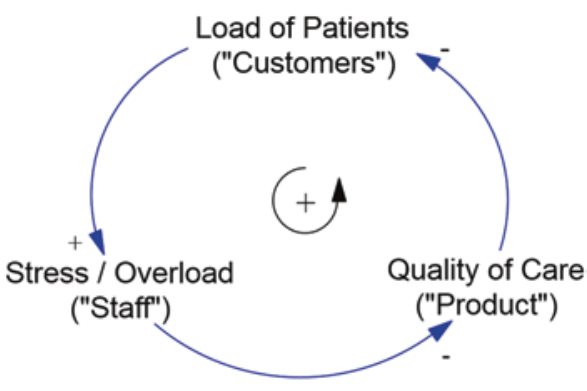

The simulations confirm all three aspects inherent in this hypothesis and, additionally, show that three tendencies reinforce each other mutually. This is shown in the high-level causal loop diagram in Fig. 4.19.

This diagram captures relationships that are in play among three perspectivescustomers, staff, and product. This high-level causal structure reveals a "mechanism" by which success and failure are brought about.

The example of the small model developed and explored here shows how a multidimensional, dynamic account of complex system behavior can be provided as a management support. This case also conveys the idea that such a model is superior to conventional management systems.

The model presented amounts to more than a punctual photography of a system state. It captures the dynamics of both the short run, with the efficiency view, and the long term, with an effectiveness perspective. If the budget is cut, the consequence is a decrease in personnel costs; this is a short-term success. However, in the long run, counterintuitive consequences emerge, not only in economic terms. More importantly, the purpose of the hospital-quality of care together with the healings quota-is affected. This difference between the short-term and long-term views is a clearly palpable instance of the distinction between efficiency and effectiveness.

It is not necessary to increase the budget, but it is imperative not to cut resources painfully. While budget cutting offers the path of least resistance, promising the relief of economic concerns, that short-termist attitude is refuted by the longer-term consequences: it paves the way to disaster. As quality erosion creeps in, the virtuous path of success is lost. Vicious circles establish themselves, before the consequences of wrong decisions become palpable. Once these vicious loops are established, there is hardly any path back to a virtuous trajectory.

Although these superintendents considered themselves the harbingers of superior performance, for the OCS, they were in fact the originators of decline, in both quality (care) and quantity (finance).This decline has not fully affected quality of care immediately, as the system showed remarkable resilience as a consequence of many years of careful strengthening. At this stage, the question remains: which path is the institutional policy going to take? 


\subsection{Context and Process: Phase II (Organizational Embedment of the Model)}

Having analyzed the content, i.e., the substantive aspects, emanating from the simulation model, it is imperative to shed light on the context: did the model have any implications for the organization under study?

In 2012, the model and the simulation results were presented to the staff of the oncological unit, who agreed with our analysis and appreciated the insights gained from it. Subsequently, however, it turned out that the impact on the governance of the unit was nonexistent. One reason could be that the management that went about cutting the budget was unreasonable, stubborn, and so on.

However, we know from research in the behavioral sciences that people are motivated by a sense of "psychological ownership," a feeling that they can lay claim to certain organizational factors as their own (Pierce et al. 2001). Such ownership fosters self-identification as well as organizational commitment and citizenship behavior (Van Dyne and Pierce 2004). The managers who initiated the budget cut had in no way been involved in the formation of the simulation model. That model had been developed rather spontaneously between the two authors. They did not consider, at that point, what in hindsight appears as a straightforward way to proceed: trying to involve the administrators in the construction of the model and using the model in the political negotiation process.

In other words, the administrators were not acquainted with the rationale developed by the doctors who were the frontline owners of that model. A much better approach for proceeding would have been to involve those managers in the discussion around the consequences of the budget cut and the construction of the model. This could have changed their mental models and prompted a different outlook on the issues at hand, giving them a grasp of the dynamics generated by their decision. The involvement in the model-building exercise would have given them a feeling of ownership and maybe led to a different decision, for example, a decision of undertaking no budget cut at all (Vennix 1996).

Hence, our proposition is that the improvement of a management system can be best obtained not only by designing a dynamic, multidimensional model but also giving decision-makers a sense of ownership of the system under development through their participation in the design process. Good models and logically cogent argumentation, based on careful studies at the content level, are necessary to trigger change in direction of a desirable future. But they are not sufficient. A context needs to be created that makes these arguments effective. In our case, the management of the hospital was not prepared adequately. They enacted their decision without an adequate understanding of its implications. 


\subsection{Conclusions: Phase II}

We have explored a path by which the reductionism in much of the established management systems can be overcome. Reverting to modeling and simulation, we have shown how multidimensional, dynamic models can be built and used to support leaders and managers more effectively in their coping with complexity. Our study uncovers a structure that generates characteristic. These conform to the expectations of the medical staff, but are counterintuitive (Forrester 1971) in the logic of the administrators. Our main finding of that kind is that the intervention of a budget cut, contrary to the expectations of the administrators, would lead to a decrease in earnings. This is probably a feature that can be found in many organizations - an archetypal structure so to say (Senge 1990; Wolstenholme 2003).

In that sense, we can assume that the structural features of our model are of a generic type. In other words, they are applicable to multiple contexts, representing a "wider class" of real-world situations (Forrester 1961: 208). Apparently, these features exist in a broad range of organizations: the patterns of behavior ascertained here, and their underlying structures can be found not only in hospitals but in any kind of public organization. Beyond that, according to our general experience, they are also relevant for private firms.

More effective steering requires more sophisticated management models. That is an insight in line with the Conant-Ashby theorem: "Every good regulator of a system must be a model of that system" (Conant and Ashby 1981). In other words, the result of a process, e.g., a management process, can only be as good as the underlying model. That is, the quality of the models used is crucial for managerial effectiveness. This article presents an application of the system dynamics methodology as an effective device for the improvement of management models. It could therefore be a useful conceptual input for those who strive to make better decisions. At the same time our study should also be of interest to researchers dealing with the design of management systems.

At this point, we also have to reflect upon the limitations of our study. First, the simulation model presented here is not complete; it does not cover all relevant variables and relationships concerning the system under study. For example, the linkages between work experience, stress, and quality of care-represented in the model - cover a fundamental qualitative feature of organizational culture. Related aspects such as systematic psycho-hygienic measures for the staff, and sustained efforts of the management to strengthen culture, are prominent in the OCS. We have refrained from quantifying these latter aspects, on purpose. However, we underline that these factors also impinge on the trajectory of the OCS and might even be the main factor warranting its resilience in this time of turbulence.

Second, management models are not a panacea against all threats and weaknesses menacing an organization. They cannot be better than the management in whose hands they rest. But the problem starts earlier. 
Third, many leaders and managers are not aware of the virtues of dynamic models and refuse them with the verdict "too complicated!" These leaders are simply unaccustomed to working with such simulations: thinking in loops, delays, and dynamic behavior is not a common practice, which means that it is not easy to "sell" modeling and simulation as something beneficial for management.

Finally, there are also certain technical barriers to the use of these models: the construction and use of good models require certain modeling skills which must either be built into the organization or acquired from outside.

We trust that these limitations are not overwhelming. Dynamic modeling and simulation are of growing importance for the quality of management. In our case, it was a useful device for organizational learning, if not at the level of the hospital management, at least within the OCS.

\section{Synopsis and Outlook}

At the core of our contribution is a real-life case study, which is long term and still ongoing. Out of the many case studies that we have realized over more than three decades, this one is the most complete. The case has been overseen by both authors over roughly 30 years. Until 2010, the organization under study was very successful. The OCS developed according to a coherent logic: growth was not assessed in terms of quantities of patients or resources. It was qualitative, reaching high levels of quality of care and effectiveness.

The long phase from 1985 to 2010 was a success story, while dark clouds surged in the second phase ranging from 2011 to 2015. At this point, two paths of future development can be discerned: either the rupture in the trend that occurred will lead the evolution of the OCS in an undesirable direction for the long term, or the OCS can regain momentum again, readjusting itself to continuing its traditional successes. For the latter to ensue, the health authorities will have to revise their financial policy.

Our research question was: "How must healthcare systems be designed to achieve viability or, more concretely, to become both efficient and effective and to maintain their identity in the long run?" Given its long-term orientation, our inquiry can provide good advice on how to build up a powerful health organization in a context of complexity and change. See conclusions of Phases I and II. The issue of effectiveness, and how to warrant it, is a pervasive topic throughout this chapter, related to high-level quality of care provided by the cybernetics-based organizational structures of the OCS. The issue of efficiency, and how to assure it, is addressed in terms of bearable cost enabled by that organizational design (Phase I) and by the systemic simulations around the economic consequences of managerial interventions (Phase II). In sum, our study yields clues about how to design a healthcare system to maintain its identity as a provider of holistic, patient-oriented care of excellent quality.

The case reports successes but also shows the downside of the upside, namely, turbulences induced by recent managerial interventions "from above." We are testing policies by which the robustness of the OCS could be enhanced. 
In line with the purpose of this chapter, which is to make a contribution toward a more effective management of healthcare organizations, we have shown a path to the enhancement of the viability of these organizations. Arguably, the most important aspect of the utility of our contribution is in that it provides insights about organizational structure and behavior which are relevant far beyond the organization analyzed in our case study. These insights are generic and applicable to a much wider class of organizations, so as to help leaders and managers in mastering complexity.

Our chapter is innovative in two respects. At the substantive level, we show advanced organization designs which reach beyond the conventional approaches to organization currently in use. The Viable System Model (VSM), a cybernetic model for organizational diagnosis and design, and the concepts of virtual and network organizations are used in the OCS for the design of the structures to enable high flexibility, agility, and productivity. As we illustrated, the dynamics generated within those structures can be captured and explored by means of system dynamics modeling and simulation.

At the methodological level, we have shown that both qualitative and quantitative methods are needed and have to be combined in order to enable effective action in the face of organizational complexity. In this sense, we provide a synthesis of the methodologies of Organizational Cybernetics and System Dynamics. The need for such a combination derives from the remarkable complexity inherent in the case under study. We are proposing a methodologically rigorous synthesis in the context of Integrative Systems Methodology, an innovative device for coping with organizational complexity.

We have structured our study in line with the categories of Integrative Systems Methodology (ISM). This way, we have provided a frame of useful distinctions for making the evolutionary process of the OCS transparent. The schema of ISM also makes palpable the method for structuring the process in a robust fashion. As the frame is multidimensional, it enables a relatively "complete" set of interventions for coping with the complexity faced in the development of the OCS. For a deeper methodological reflection of ISM, see Schwaninger (2013).

The ISM-framework has been used in multiple organizations. In the case under study, it has been applied over a long time; the results in terms of both efficiency and effectiveness have been outstanding. However, this finding is the smaller part of the theoretical harvest reaped from our study. Beyond the substantive results concerning the organization in focus, the data gathered from our inquiry lead to generic insights about organizational dynamics (see the above sections with the conclusions for each phase): insights that are applicable to a large class of organizations, not merely to this case study.

Acknowledgments The authors wish to express their gratitude to all the people who have taken part in developing Oncology Carinthia for their enormous dedication and wonderful care: from the cleaning staff to doctors, nurses, administrators, and state authorities. Our thanks also go to Prof. Hassan Qudrat' Ullah for his helpful editorial support. Finally, we are grateful to Ms. Evgenia Ushakova for her precious help in statistical matters and to Dr. John Peck for his excellent revision of our text. 


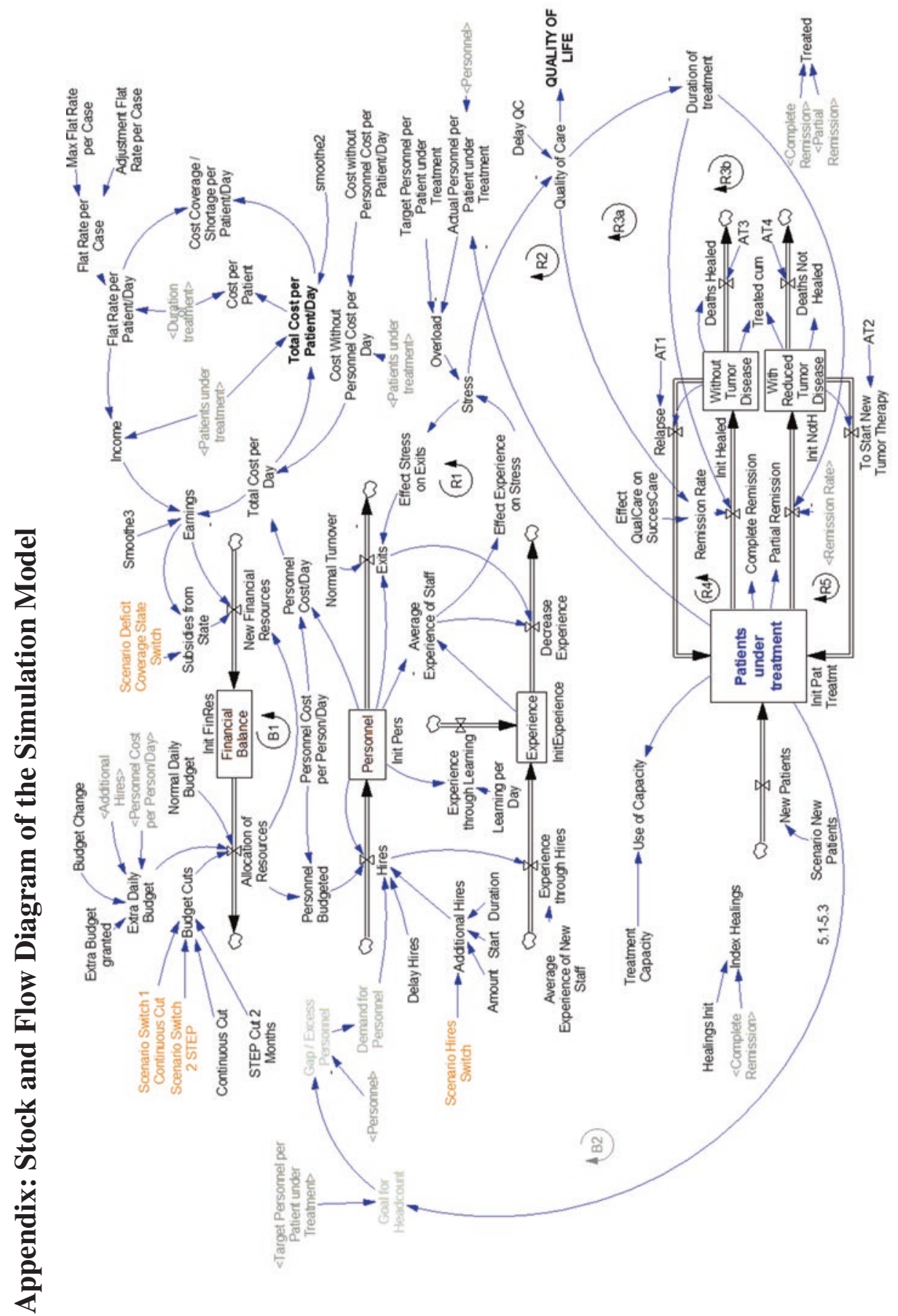




\section{References}

Antonovsky, A. (1987). Unraveling the mystery of health - how people manage stress and stay well. San Francisco: Jossey-Bass.

Ashby, W. R. (1956). An introduction to cybernetics. London: Chapman \& Hall.

Barlas, Y. (1996). Formal aspects of model validity and validation in system dynamics. System Dynamics Review, 12(3), 183-210.

Beer, S. (1979). The heart of enterprise. Chichester: Wiley.

Beer, S. (1981). The brain of the firm. Chichester: Wiley.

Beer, S. (1984). The viable system model: Its provenance, development, methodology and pathology. Journal of the Operational Research Society, 35(1), 7-25.

Beer, S. (1985). Diagnosing the system for organizations. Chichester: Wiley.

Beer, S. (1994). Beyond dispute. The invention of team syntegrity. Chichester: Wiley.

Birkinshaw, J., Hamel, G., \& Mol, M. J. (2008). Management innovation. Academy of Management Review, 33(4), 825-845.

Boos, F., \& Mitterer, G. (2014). Einführung in das systemische management. Heidelberg: CarlAuer-Systeme Verlag.

Brewer, J., \& Hunter, A. (2006). Foundations of multimethod research: Synthesizing styles. Thousand Oaks: Sage.

Conant, R. C., \& W. R. Ashby. (1981, originally published in 1970). Every good regulator of a system must be a model of that system. In R. C. Conant (Ed.), Mechanisms of intelligence: Ross Ashby's Writings on cybernetics (pp. 205-214). Seaside: Intersystems Publications.

Crisan Tran, C.I. (2006). Beers viable system model und die Lebensfähigkeit von Jungunternehmen: eine empirische Untersuchung, Ph.D. Dissertation. University of St. Gallen, No. 3201.

Dangerfield, B. (2014). In S. Brailsford, L. Churilov, \& B. Dangerfield (Eds.), Systems thinking and system dynamics: A primer. Discrete-event simulation and system dynamics for management decision making (pp. 26-51). Chichester: Wiley.

Erbsen, A. (2012). Krankheit im Zentrum Gestaltung von krankheitsorientierten Spitalstrukturen aus kybernetisch -konstruktivistischer Sicht. Wiesbaden: Springer Fachmedien Wiesbaden.

Espejo, R. (1993). Management of complexity in problem solving. In R. Espejo \& M. Schwaninger (Eds.), Organizational fitness: Corporate fitness through management cybernetics (pp. 67-92). Frankfurt: Campus.

Espejo, R., \& Reyes, A. (2011). Organizational systems. Managing complexity with the viable system model. Berlin: Springer.

Espejo, R., Schuhmann, W., Schwaninger, M., \& Bilello, U. (1996). Organizational transformation and learning. A cybernetic approach to management. Chichester: Wiley.

Flood, R. L., \& Jackson, M. C. (1991). Creative problem solving. Total systems intervention. Chichester: Wiley.

Forrester, J. W. (1961). Industrial dynamics. Cambridge: MIT Press.

Forrester, J. W. (1971). Counterintuitive behavior of social systems. Technology Review, 73(3), $52-68$.

Forrester, J. W., \& Senge, P. M. (1980). Tests for building confidence in system dynamics models. In A. A. J. Legasto, J. W. Forrester, \& J. M. Lyneis (Eds.), System dynamics. Amsterdam.

Golden, S. L. (2017). In C. Garcia-Díaz \& C. Olaya (Eds.), Compromised exactness and the rationality of engineering. Social systems engineering. Chichester: Wiley. Forthcoming.

Gomez, P., \& Probst, G. J. B. (1987). Vernetztes denken im management. Die orientierung (89). Bern: Schweizerische Volksbank.

Hammond, D. (2003). The science of synthesis: Exploring the social implications of general systems theory. Boulder: University Press of Colorado.

Hoverstadt, P. (2008). The fractal organization. Creating sustainable organizations with the viable system model. Chichester: Wiley. 
Laszlo, E. (1996). The systems view of the world. Cresskill: Hampton Press.

Lipnack, J., \& Stamps, J. (2000). Virtual teams (2nd ed.). New York: Wiley.

Luhmann, N. (1995). Social systems. Stanford: Stanford University Press.

Malik, F. (2008). Strategie des managements komplexer systeme. Ein Beitrag zur managementKybernetik evolutionärer Systeme (10th ed.). Bern: Haupt.

McCulloch, W. (1965; new edition 1988). Embodiments of mind. Cambridge, MA: MIT Press.

Mingers, J., \& Gill, A. (Eds.). (1997). Multimethodology. The theory and practice of combining management science methodologies. Chichester: Wiley.

Morgan, D. L. (2014). Integrating qualitative and quantitative methods: A pragmatic approach. Thousand Oaks: Sage.

Nonaka, I., \& Takeuchi, H. (1995). The knowledge-creating company. New York: Oxford University Press.

Pérez Ríos, J. (2012). Design and diagnosis for sustainable organizations: The viable system method. Berlin: Springer.

Pettigrew, A. M. (1985). The awakening giant: Continuity and change in imperial chemical industries. Oxford: Blackwell.

Pierce, J. L., Kostova, T., \& Dirks, K. (2001). Toward a theory of psychological ownership in organizations. Academy of Management Review, 26, 298-310.

Richardson, G. (1997). Problems in causal loop diagrams revisited. System Dynamics Review, 13(3), 247-252.

Schwaninger, M. (1997). Integrative systems methodology: Heuristic for requisite variety. International Transactions in Operational Research, 4, 109-123.

Schwaninger, M. (2003). A cybernetic model to enhance organizational intelligence. Systems Analysis Modelling Simulation, 43(1), 53-65.

Schwaninger, M. (2004). Methodologies in conflict. Achieving synergies between system dynamics and organizational cybernetics. Systems Research and Behavioral Science, 21, 1-21.

Schwaninger, M. (2006). Design for viable organizations: The diagnostic power of the viable system model. Kybernetes, 35(7/8), 955-966.

Schwaninger, M. (2009). Intelligent organizations: Powerful models for systemic management (2nd ed.). Berlin: Springer.

Schwaninger, M. (2013). An integrative systems methodology for dealing with complex issues. In J. Zelger, J. Müller, \& S. Plangger (Eds.), GABEK VI - sozial verantwortliche Entscheidungsprozesse (pp. 177-196). Innsbruck: Studien Verlag.

Schwaninger, M., \& Groesser, S. (2011). In R. A. Meyers (Ed.), System dynamics modeling: Validation for quality assurance. Complex systems in finance and econometrics (Vol. 2, pp. 767-778). New York: Springer Science+Business Media.

Schwaninger, M., \& Klocker, J. (2017a). In C. García-Díaz \& C. Olaya (Eds.), Holistic systems design: The oncology Carinthia study. Social systems engineering. Chichester: Wiley. Forthcoming.

Schwaninger, M. \& Klocker, J. (2017b). Efficiency versus effectiveness in hospitals: A dynamic simulation approach. Outcome-based performance management in the public sector. Eds. E. Borgonovi, E. Anessi Pessina, and C. Bianchi. Forthcoming.

Schwaninger, M., \& Scheef, C. (2016). Testing the viable system model. Theoretical claim versus empirical evidence. Cybernetics and Systems , 47, 544. doi:10.1080/01969722.2016.1209375. August 2016

Senge, P. M. (1990). The fifth discipline. The art and practice of the learning organization. London: Century Business.

Sterman, J. D. (1984). Appropriate summary statistics for evaluating the historical fit of system dynamics models. Dynamica, 10(2), 51-66.

Sterman, J. D. (2000a). Business dynamics. Systems thinking and modeling for a complex world. Boston: Irwin/Mc Graw-Hill.

Tashakkori, A., \& Teddlie, C. (1998). Mixed methodology: Combining qualitative and quantitative approaches. Thousand Oaks: Sage. 
Tashakkori, A., \& Teddlie, C. (2010). Sage handbook of mixed methods in social and behavioral research. Thousand Oaks: Sage.

Theil, H. (1966). Applied economic forecasting. Chicago: Rand McNally.

Ulrich, H. (2001). Gesammelte schriften. Bern: Haupt.

Van Dyne, L., \& Pierce, J. L. (2004). Psychological ownership and feelings of possession: Three field studies predicting employee attitudes and organizational citizenship behavior. Journal of Organizational Behavior, 25, 439-459.

Vennix, J. A. M. (1996). Group model building: Facilitating team learning using system dynamics. Chichester: Wiley.

von Bertalanffy, L. (1968). General system theory. New York: Braziller.

Weber, M., \& Schwaninger, M. (2002). Transforming an agricultural trade organization: A systemdynamics-based intervention. System Dynamics Review, 18(3), 381-401.

Wiener, N. (1948). Cybernetics or control and communication in the animal and the machine. Cambridge: MIT Press.

Wolstenholme, E. F. (2003). Towards the definition and use of a core set of archetypal structures in system dynamics. System Dynamics Review, 19(1), 7-26.

Ziegler, A., Lange, S., \& Bender, R. (2007). Überlebenszeitanalyse: Der log-rang test. Deutsche Medizinische Wochenschrift, 132, e39-e41. 